\title{
ATRIBUCIÓN Y SUS LÍMITES: ATRIBUTO, PREDICATIVO Y COMPLEMENTO DE MODO ${ }^{1}$
}

\author{
José LUIS CifuenTES HONRUBIA \\ Universidad de Alicante \\ cifu@ua.es
}

\begin{abstract}
Resumen
En este trabajo analizamos los límites entre distintas construcciones (atributo, predicativo y complemento de modo), y demostraremos que existe un continuo entre las mismas, a la vez que señalaremos las pautas sintácticas y semánticas que rigen su funcionamiento y sus interferencias. Demostraremos también que los sintagmas preposicionales pueden funcionar como predicativos descriptivos al estar marcados gramaticalmente con diversas pautas de funcionamiento.
\end{abstract}

PALABRAS CLAVE: atributo, predicativo, complemento de modo, predicativo descriptivo.

\begin{abstract}
This paper examines the boundaries between different constructions (attribute, predicative and manner adjunt), and we will demonstrate that there is a continuum between them, as well as we will point out the syntactic and semantic patterns governing its functioning and its interference. We will also show that prepositional phrases can function as depictive predicatives because they are grammatically marked with various patterns of functioning.
\end{abstract}

KEY WORDS: attribute, predicative, manner adjunt, depictive.

\section{La atribución y sus límites}

En español hay una amplia tradición en la consideración de los límites de la atribución, en el sentido de incluir predicativos y atributos formando parte de una misma unidad funcional ${ }^{2}$. Nuestra postura ante la atribución no parte de la definición estricta tradicional que aglutina en ella única y exclusivamente a aquellos complementos intro-

\footnotetext{
${ }^{1}$ Este trabajo forma parte del proyecto de investigación FFI2010-19946, financiado por el Ministerio de Ciencia e Innovación del Gobierno de España, y constituye una ampliación y reelaboración del artículo "Predicativo y complemento de modo", publicado en Enghels, R., M. Meulleman \& C. Vanderschueren (2011) (eds.): Peregrinatio in Romania. Artículos en homenaje a Eugeen Roegiest con motivo de su 65 cumpleaños. Gante: Academia Press, págs. 51-78.

2 Vid. al respecto los planteamientos de Navas Ruiz (1977), Rodríguez Díez (1982), Porroche (1990), Gutiérrez Ordóñez (1986, 1995), Penadés (1994), o Fernández Leborans (1999), donde se recogen diversas posturas al respecto.
} 
ducidos por un verbo copulativo y que, por ello, pueden conmutarse por el neutro $l o$. Consideramos el concepto funcional metodológico de "atribución" como la incorporación u orientación de un determinado concepto (propiedad, estado o cualidad) hacia una base concreta de atribución (sujeto, OD, etc). Ahora bien, la clase de los atributos que cumplen esta función es una gran bolsa en la que es posible diferenciar subclases y que se opone, globalmente, al resto de las funciones sintácticas.

Esta idea de "gran bolsa" podemos estructurarla más adecuadamente bajo la consideración de una categorización prototípica, entendida como efectos prototípicos (Cifuentes, 1994: cap. IV), es decir, que hay diferencias entre los elementos que cumplen un determinado concepto funcional de atribución. La categoría prototípica vendrá caracterizada por una serie determinada de rasgos, cuya distinta combinatoria puede dar origen, por ejemplo, a la tradicional diferencia entre atributo y predicativo. Algunos de los rasgos pueden ser los siguientes:

a) Orientación de un concepto hacia una base atributiva.

b) Conmutación por un pronombre de naturaleza neutra (lo, eso).

c) Conmutación por el adjetivo-adverbio así.

d) Concordancia de género y número entre la base atributiva y el atributo.

e) Anteposición del complemento atributo respecto del sintagma nominal.

f) No conmutación junto a la base atributiva.

g) Contenido léxico de todos los verbos susceptibles de desarrollar un complemento atributivo.

h) Mitigación del contenido léxico de algunos verbos.

i) Carácter icónico de la movilidad oracional del complemento atributivo.

j) Incidencia en distintos participantes del evento verbal.

k) Posibilidad de incidencia del evento verbal en la selección del complemento atributivo.

1) Carácter obligatorio u opcional.

m) Predicación secundaria o primaria.

En el interior de la función atributiva hallamos diversos subconjuntos funcionales que cumplen algunos o la totalidad de los rasgos característicos que definen e identifican a la atribución, sin que ello disminuya en absoluto la mayor o menor potencialidad atributiva de cualquiera de ellos. Simplemente existirán ciertas subclases atributivas que satisfarán un número más elevado de rasgos atributivos que otros, pero todos ellos pertenecerán a la función de la atribución. 


\section{Atributos copulativos y predicativos}

Los atributos copulativos son aquellos que se configuran a partir de un verbo denominado copulativo, cuya característica fundamental es la posesión de un significado léxico mitigado en favor de un significado gramatical, convirtiéndolos, casi de forma exclusiva, en meros elementos de enlace entre un tema atributivo y el atributo (el pintor es feliz).

Junto a los atributos copulativos se encuentran los predicativos, aquellos que no poseen como núcleo verbal un verbo gramaticalizado que pierde parte de su valor léxico en favor de un cambio de significado, una modificación hacia un contenido esencialmente relacional. Los predicativos, al contrario de lo que sucedía con los atributos copulativos, permiten la posibilidad de elidir el atributo, no creando frases agramaticales si este hecho se produce (Irene sonrió contenta / Irene sonrió).

Así pues, si entendemos por atributo "la función que desempeñan varios grupos sintácticos que denotan propiedades o estados de cosas que se predican del referente de algún segmento nominal u oracional" (RAE, 2009: 2773), tan atributos son los copulativos como los predicativos. Ahora bien, lógicamente no son iguales, pareciendo consistir la diferencia, fundamentalmente, en el tipo de verbo: copulativo vs. predicativo o léxico. Fernández Leborans (1999) recuerda adecuadamente la polémica de diferenciación de los dos tipos de verbos, que originan dos funciones diferenciadas: los verbos copulativos se caracterizarían por su contenido semántico nulo o vacío, debido a un proceso de gramaticalización, lo que les confiere expresar estado o cualidad. Por el contrario, los verbos predicativos serían semánticamente plenos, y expresarían, en general, acción o proceso. No obstante, formalmente estarían diferenciados por el hecho de la conmutación del atributo por la forma $l o$, solo posible en oraciones con verbos propiamente copulativos. El problema fundamental estribaría en que hay verbos pseudocopulativos o semiatributivos que se situarían en una frontera difusa a ambos lados de la diferenciación. Fernández Leborans (1999: 2362) establece que el límite entre las dos clases de verbos no es preciso. No obstante, llega a diferenciar los verbos copulativos por las siguientes características:

a) No imponen restricciones de selección a su sujeto.

b) Son verbos desemantizados o gramaticalizados.

c) Son auxiliares de predicación, en el sentido de que capacitan al predicado nominal para desempeñar función de predicado oracional. 
d) Forman con el atributo una especie de predicado complejo no disociable, es decir, el atributo no es un predicado secundario, no siendo prescindible ninguno de sus dos constituyentes, y siendo su núcleo léxico una categoría nominal.

Los verbos predicativos, por el contrario, seleccionarían un sujeto semántico, poseerían contenido léxico pleno, $y$, en su mayor parte, admitirían predicados nominales secundarios. Demonte y Masullo (1999: 2466) señalan que la única diferencia formal entre predicativos y atributos parece residir en la sustitución por lo. No obstante, aun siendo interesante esta propiedad, debemos señalar que no tiene un funcionamiento "perfecto", pues parecer, por ejemplo, tiene tanto usos predicativos como copulativos y posibilita la sustitución por $l o$. Y aun aceptando parecer al mismo nivel funcional que ser, la prueba de la sustitución debemos cuestionarla en muchas ocasiones. Pensemos, por ejemplo, en casos como los siguientes, en los que la aceptabilidad de la sustitución por lo es, cuando menos, dudosa:

\section{La fiesta fue muy bonita / ¿? Lo fue.}

El vino era de Jerez / ¿?Lo era.

Demonte y Masullo (1999: 2463-2469) definen los predicativos como constituyentes que modifican simultáneamente al predicado verbal y a un sintagma nominal de la misma oración: en Irene sonrió contenta, el predicativo contenta indica una propiedad de Irene y expresa también que ese estado se manifiesta asociado al acto de sonreír. Así pues, con 'predicativo' se expresa que estos modificadores se comportan respecto del nombre como un segundo predicado, al atribuirle una propiedad, cualidad o estado, y tienen con él una relación de dependencia sintáctica que se traduce en concordancia de género y número cuando es un adjetivo. Para la RAE (2009: 2864) el predicativo es una variante del atributo, y coincide prácticamente con la definición de Demonte y Masullo, pues lo considera una expresión atributiva que se predica de un grupo nominal, o de una oración, a través de un verbo principal o pleno, por tanto, de un verbo que no sea copulativo ni pseudocopulativo. Este hecho, es decir, constituir un predicado subordinado a otro predicado principal, permite su consideración como predicado secundario (2009: 2779-2780).

Demonte y Masullo recogen una serie de pruebas que demuestran la naturaleza funcional distinta de los complementos predicativos y de los adjetivos en función de modificadores directos del nombre y de los complementos nominales en general: 1) Los predicativos no se ven afectados por la pronominalización del sintagma nominal al que modifican: Lavé la camisa sucia > la lavé sucia /la lavé. 2) Los complementos predicativos pueden separarse del nombre al que modifican y aparecer a continuación del verbo al que se refieren, es decir, se pueden anteponer al SN al que modifican: Guardó la ca- 
misa sucia $>$ guardó sucia la camisa. 3) Los predicativos pueden anteponerse al resto de la oración: sucia me devolviste la camisa. 4) Los predicativos permanecen en el sintagma verbal en las construcciones pasivas correspondientes a activas con predicativo de objeto: la camisa fue guardada/se guardó sucia vs. la camisa sucia fue guardada/se guardó.

\section{Atributos no copulativos}

Tanto Demonte y Masullo (1999: 2511) como la RAE (2009: 2838-2864) establecen distintos tipos de verbos pseudo- o semicopulativos, intermediarios entre copulativos y predicativos. Así, Demonte y Masullo hablan de a) verbos de cambio de estado y resultado (poner, quedar, volver, etc.), b) verbos de movimiento desemantizados (ir, andar, salir, etc.), c) verbos auxiliares aspectuales (empezar, continuar, terminar, etc.), d) verbos de percepción desemantizados (verse, oirse, etc.). La RAE establece una clasificación parecida. En cualquier caso, lo interesante es que una construcción como el marido se volvió egoísta encajaría perfectamente en la definición de verbo copulativo dada, no así en la de verbo predicativo o léxico, (Fernández Leborans, 1999: 2363): a) no es el verbo el que determina la selección del sujeto, sino el atributo: ${ }^{*}$ el agua se volvió triste, ${ }^{*}$ Ana se volvió turbia. b) Volverse, en el ejemplo propuesto, es un verbo desemantizado o gramaticalizado, expresando, fundamentalmente, valores aspectuales. c) En el ejemplo propuesto, el marido se volvió egoísta, volver funciona como auxiliar de predicación, en el sentido de que facilita la predicación a través del atributo. d) El atributo no es un predicado secundario, pues no son prescindibles ninguno de los dos constituyentes: ${ }^{*} e l$ marido se volvió. e) El atributo no se comporta como un adjunto adverbial, denotando un estado concurrente con el evento denotado por el verbo: en el marido se volvió egoísta sólo es posible reconocer un evento que es el cambio de estado especificado por el atributo egoísta.

No obstante lo anterior, no todos los verbos pseudocopulativos tienen el mismo comportamiento en todos sus usos:

Juan volvió a su casa / Juan volvió tonto a su casa /Juan volvió tonto /Juan volvió tonto a Pedro / Juan volvió a Pedro / Juan se volvió tonto / Juan se volvió.

Volver se comporta como verbo de desplazamiento con predicativos de sujeto, y en las construcciones proyectadas no podemos decir que el verbo pierda su significado local. Por el contrario, con predicativos de objeto, o en muchas ocasiones con predicativos de sujeto bajo la forma volverse, no hay restos de significado local, es un verbo aspectual, $y$, como tal, parangonable a las construcciones atributivas. Así pues, parece haber una asociación entre la pérdida de significado verbal, asumiendo valor copulativo con contenidos aspectuales, y la necesidad del atributo. Si el verbo es imposible de cons- 
truir sin el atributo, al menos sin dudas al respecto, podríamos establecerlo como un límite para diferenciar copulativos de predicativos, y por ello también de predicación secundaria. En los casos comentados con volver, es clara la agramaticalidad de las construcciones transitivas sin CD. En cuanto a las construcciones intransitivas, para ser consideradas gramaticales, deben ser entendidas con un significado local, nunca gramaticalizado aspectualmente, pues de ser así sería necesario el atributo. De alguna forma, por tanto, podríamos establecer un continuo en el grado de desemantización semántica verbal, paralelo igualmente a la prescindencia o no del atributo, siendo ser, estar y parecer los típicos verbos atributivos, distintos de los verbos pseudocopulativos desemantizados, que también expresan cópula, y que pueden tener usos nos gramatizalidos con predicativo, a semejanza del conjunto general de verbos que se combinan con predicativos:

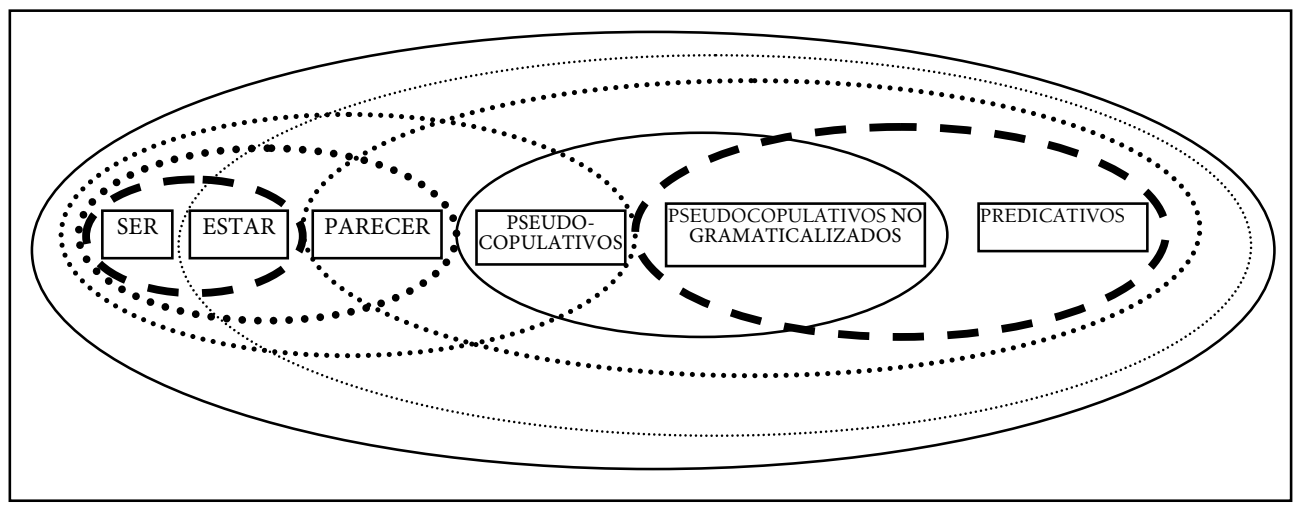

Figura 1: Continuo entre verbos copulativos y verbos predicativos.

Solo hemos ejemplificado el continuo con algunos grupos de verbos, y a partir de las características comentadas, pero es obvio que podrían considerarse más grupos de verbos. Una vez establecido el continuo, los límites entre verbos copulativos y verbos predicativos pueden establecerse según las pautas del análisis. Así, una manera de establecer el corte divisorio podría estar en la necesaria gramaticalización que conlleva la aparición de una estructura atributiva, al perder el verbo parte de su contenido léxico, corte que podríamos establecer en volver(se), y similares, pues manifiesta claramente una desemantización en el significado, distinto, por otro lado, de las estructuras predicativas que conlleva como verbo pleno con predicación secundaria, aunque con un alcance en un controlador distinto.

Son muy pocos los usos de ser no copulativos. Estar permite usos copulativos y no copulativos (locales). Parecer puede tener también dos valores: copulativo y verbo de 
cognición. Volver tiene dos significados: a) local, que puede llevar predicativos de sujeto con predicación secundaria, b) copulativo, bajo la forma volverse afectando al sujeto, y como volver como predicación primaria afectando a un atributo no copulativo de CD. Otros verbos predicativos pueden tener usos predicativos, como predicación secundaria, bien de sujeto bien de complemento directo, sin cambio de significado. Vemos, por tanto, que el funcionamiento es teóricamente similar en todos ellos.

\section{Predicativos obligatorios y opcionales}

Si los límites entre predicativos y atributos son difusos, los dados entre predicativos obligatorios y predicativos opcionales, obviamente, también. Para algunos autores, la noción de predicado secundario también incluye construcciones en las que el elemento predicativo secundario no es un adjunto sino un complemento, es decir, de alguna manera viene seleccionado por la predicación principal, y es por ello obligatorio: lo eligieron presidente, y ello tanto en la bibliografía hispánica (Demonte y Masullo, 1999; Gumiel, 2005, 2008, RAE, 2009) como en la internacional (Halliday, 1967; Nichols, 1978; Napoli, 1989). Himmelmann y Schultze (2005: 24-25) admiten que hay relaciones funcionales y formales entre predicativos obligatorios (o complementos) y los descriptivos como predicativos opcionales (o adjuntos): funcionalmente, ambos están orientados hacia el participante, y significan en parte una predicación independiente acerca de un participante de la predicación principal. De todas formas, la distinción entre unos y otros no parece ser otra que el tan debatido problema de la distinción general entre complementos y adjuntos ${ }^{3}$.

Van der Auwera y Malchukov (2005: 406-410) consideran que, al menos en algunos casos, hay predicativos obligatorios que pueden ser considerados como predicaciones primarias, aunque subordinadas: Considero a John inteligente $>$ Considero a John ser inteligente > Creo que John es inteligente. Como más tarde comentaremos con detenimiento, la idea esbozada es que los predicativos obligatorios no constituyen una predicación secundaria, sino una predicación primaria. En ese sentido, son más propiamente parecidos a los atributos de los verbos copulativos y pseudocopulativos, en tanto que suponen una predicación sobre un estado, cualidad o propiedad acerca de una determinada base de atribución, pero se diferencian de ellos en que están vinculados a verbos predicativos en general, de ahí su vinculación con los predicativos opcionales, es decir

\footnotetext{
${ }^{3}$ Es muy interesante al respecto el trabajo de Dowty (2003), donde discute las similitudes entre adjuntos y complementos y las transiciones históricas entre los mismos.
} 
están vinculados por el tipo de verbo implicado, en principio no gramaticalizado en su significado.

Si tomamos como base de nuestro análisis la clasificación de Demonte y Masullo (1999: 2471) de complementos predicativos obligatorios, intentaremos explicar en todos los casos la ausencia de predicación secundaria:

1) Predicativos en construcciones transitivas complejas o con 'cláusulas mínimas':

a) Predicativos en CM de verbos epistémicos, volitivos y de orientación prospectiva.

b) Predicativos en CM exigidas por verbos causativos.

2) Predicativos en oraciones con verbos soporte o de apoyo.

3) Complementos predicativos seleccionados por verbos intransitivos:

a) Predicativos de verbos 'pseudo-copulativos' y similares.

b) Predicativos introducidos por preposición.

En el caso de los intransitivos, ya comprobamos que los predicativos de los verbos pseudocopulativos y similares podían ser asimilables a los atributos de los verbos copulativos, de ahí su denominación de atributos no copulativos. Por ejemplo: Juan volvió tonto a su casa, que lo consideramos predicativo, implica que Juan volvió a su casa, siendo el predicativo opcional, por tanto. Por el contrario, en casos como Juan volvió tonto a Pedro ${ }^{4}$ Juan se volvió tonto no podemos afirmar que impliquen Juan volvió a Pedro o Juan se volvió, siendo, por tanto, casos de predicativo obligatorio asimilable a los atributos, principalmente porque el verbo ha gramaticalizado su significado y su necesidad sintáctica, haciéndolo más abstracto, y semejante, por ello, a los verbos atributivos.

De igual forma, en otro ejemplo de verbo pseudocopulativo como Juan se puso triste, no podemos decir que esa oración implique Juan se puso. No hay, por tanto, una predicación secundaria, concomitante o no, a la predicación principal. El cambio de significado en el verbo, que entraña una mayor abstracción producto de la gramaticalización, ocasiona que no se desarrolle una predicación secundaria, sino una predicación primaria. Es decir, el verbo, en estos casos, necesita el atributo para poder completar el significado, pudiendo constituir, si se quiere, un predicado complejo. Podríamos, por tanto, hablar de un atributo no copulativo, es decir, de un atributo que se da con verbos que no son los tradicionalmente considerados copulativos: ser, estar y parecer.

\footnotetext{
${ }^{4}$ Contrariamente a Demonte y Masullo, consideramos que hay muchas construcciones transitivas con verbos pseudocopulativos.
} 


\subsection{Verbos pseudocopulativos y similares}

El primer grupo de verbos pseudocopulativos que Demonte y Masullo comentan es el de los verbos de cambio de estado y resultado, que son los ejemplos que acabamos de ver con ponerse y volverse. El segundo grupo es el de los verbos de movimiento desemantizados, que, al igual que los verbos de cambio de estado y resultado, pueden tener usos atributivos o usos predicativos: en los usos atributivos el verbo está desemantizado y no conforma una predicación secundaria, siendo el predicativo obligatorio, por tanto un atributo no copulativo. En los usos predicativos opcionales, el verbo es considerado pleno y expresa una predicación secundaria:

Luis me cayó pesado: atributo no copulativo, obligatorio, y verbo gramaticalizado. La construcción no implica Luis me cayó o, simplemente, Luis cayó. Por el contrario, una construcción como Luis cayó ladeado supone un tipo de predicativo opcional, y el verbo pleno, pudiendo hablar, por tanto, de una predicación secundaria: la construcción implica que Luis cayó.

El tercer grupo de verbos que Demonte y Masullo comentan es el de los verbos auxiliares aspectuales. En este caso, la pauta de funcionamiento es igual a la ya vista: el verbo tiene fundamentalmente un contenido aspectual, el predicativo es obligatorio, y no hay predicación secundaria (un atributo no copulativo, por tanto): Juan acabará tonto no implica Juan acabará. Como muy bien dicen Demonte y Masullo (1999: 2515), los verbos de este tipo no son usados con su significado pleno, sino que hacen referencia a un evento en el que el sujeto de la oración se encuentra en un determinado estado, es decir, estos verbos seleccionan un evento en el que se describe una relación entre el sujeto oracional y su complemento. Compárese, por ejemplo, la construcción la situación continúa crítica, en la que el verbo tiene un contenido aspectual, desemantizado, siendo el predicativo obligatorio (atributo no copulativo), y sin predicación secundaria (la construcción no implica la situación continúa), con una construcción como Juan continuó el trabajo entusiasmado, donde sí está implicada la construcción Juan continuó el trabajo, siendo el predicativo, por tanto, opcional, y la predicación secundaria.

El último grupo de verbos pseudocopulativos que Demonte y Masullo analizan es el de los verbos de percepción destransitivizados. Al igual que en los grupos anteriores, podemos encontrar ejemplos en los que el verbo tiene algún tipo de desemantización, siendo el predicativo obligatorio (atributo no copulativo), y la predicación primaria: te ves espléndida no implica te ves. Por el contrario, estos mismos verbos pueden tener vertiente predicativa en usos transitivos, siendo el predicativo opcional y la predicación secundaria: vi el vestido manchado implica vi el vestido. 
Así pues, el grupo de verbos pseudocopulativos, en sus usos atributivos no copulativos, es decir, cuando funcionan desemantizados, no comportan una predicación secundaria, sino primaria, patente, por otro lado, en la necesidad funcional del complemento atributivo. El problema, y lo interesante, es que estos mismos verbos pueden desarrollar, en muchos casos, usos con valor pleno, pudiendo hacer aparecer un predicativo opcional en forma de una predicación secundaria. Ni qué decir tiene que, en muchos casos, y debido al continuo de gramaticalización, será difícil discernir si estamos en un funcionamiento u otro.

\subsection{Verbos predicativos introducidos por preposición}

El segundo grupo de verbos intransitivos con predicativo obligatorio seleccionado por Demonte y Masullo es el de los verbos predicativos introducidos por preposición. No se trata en estos casos de predicativos preposicionales, sino de verbos que rigen preposición construidos con predicativos, con fuertes conexiones, por tanto, con las construcciones con verbos de régimen preposicional. La gramática española también ha señalado tradicionalmente algunas áreas de conexión entre complemento preposicional y atributo/predicativo. Tanto Alarcos (1990) como Martínez García (1986) hablaban de un suplemento atributivo en construcciones como

El presidente pasa por tonto

Habéis pecado de ingenuos

Os tenéis por inteligentes

Cano Aguilar (1999: 1841) considera que hay que distinguir entre verbos de régimen preposicional que se construyen con atributo preposicional (como los ejemplos anteriores), y verbos que pueden llevar un adjetivo dentro, como alardear, presumir o acusar, donde la preposición pertenece al régimen general del verbo, y que incluso pueden permitir la coexistencia de atributo y complemento de régimen preposicional con adjetivo: presumía muy orgulloso de seductor con las mujeres. La mera concordancia no basta para hablar de función atributiva, pues en María presume de guapa hay concordancia, pero es la misma función sintáctico-semántica que en María presume de su belleza. Moure (1995: 123-126) también considera áreas intermedias entre complemento preposicional y predicativo, lo que no quiere decir que ambos puedan igualarse. En cualquier caso, lo que sí está claro es que estos verbos no constituyen predicación secundaria ni estructura pseudocopulativa alguna. Resulta difícil hablar en todos los casos de usos bien desemantizados bien metafóricos, frente a otros usos 'rectos' no desemantizados (pecar de ingenuo vs. pecar), pues afirmamos que se predica una determinada 
cualidad, propiedad o estado de un sujeto de la atribución, por lo que, debido al carácter obligatorio del predicativo, podríamos hablar de un atributo no copulativo y de una predicación primaria, no secundaria. Evidentemente estos verbos también constituirán un continuo, pero en una dimensión distinta a la establecida más arriba con los verbos pseudocopulativos. El continuo iría desde los verbos propiamente copulativos (ser, junto con estar y parecer), pasando por los verbos mencionados por Fernández Leborans, es decir, verbos con atributo no copulativo en los que el predicativo es obligatorio y la predicación primaria, diferenciados de los anteriores en que no son verbos propiamente copulativos, y posteriormente pasaríamos a los verbos predicativos no atributivos. Junto a ellos estarían los verbos de régimen preposicional que se combinan con predicativos, los verbos de régimen preposicional que pueden combinarse con adjetivo, o con otro elemento, $y$, por último, los verbos de régimen preposicional que no se construyen con adjetivos:

La casa era de sus abuelos

La cama está sin hacer

Parecía de mármol

Pecó de ingenuo

Presume de guapa

Presume de su belleza

Habla de política

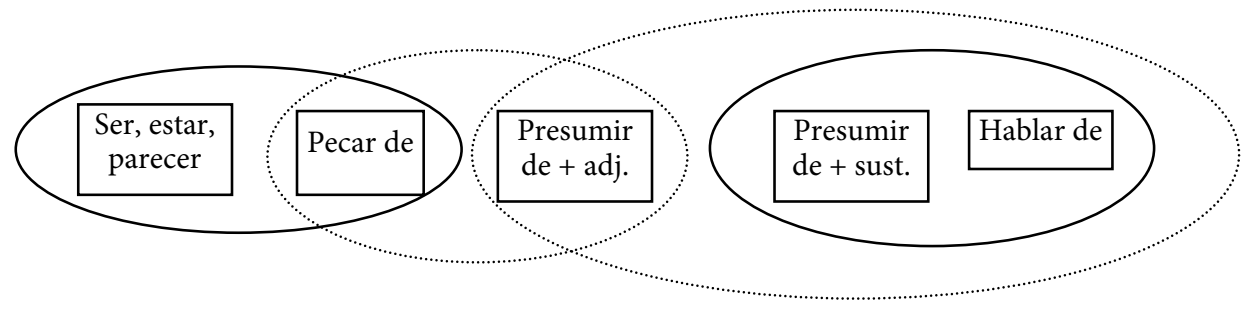

\subsection{Predicativos con verbos de apoyo}

El segundo grupo de predicativos obligatorios establecido por Demonte y Masullo (1999: 2508-2510) es el de los dados en oraciones con verbos soporte o de apoyo. Debido a la desemantización de los verbos soporte, estos van acompañados de un sintagma nominal que completa su significado. No obstante, en ocasiones, algunos de estos verbos se construyen con complementos predicativos formando un predicado complejo en 
el que el verbo de apoyo aporta el valor categorial y aspectual, y el predicativo el significado. Evidentemente este predicativo requiere una base nominal a la que referirse. Por ejemplo, construcciones como Juan tenía las manos sucias o habla español tan mal que lo tomaron por extranjero son consideradas ejemplos de predicativos obligatorios con verbos soporte. En ambos casos encontramos coincidencias con el primer grupo tratado (los verbos pseudocopulativos), pues el predicativo es obligatorio, hay algún tipo de desemantización en el verbo, y no hay predicación secundaria, pudiendo por ello ser considerados como atributos no copulativos, al predicar una propiedad, cualidad o estado respecto de una base de atribución determinada (sujeto o CD). En el caso de habla español tan mal que lo tomaron por extranjero, es claro que el predicativo (introducido por preposición) es obligatorio, no es prescindible, y que la construcción no implica lo tomaron, principalmente porque tomar está desemantizado, entre otras razones porque siendo un verbo de acción física pasa a significar una acción intelectual. La vinculación entre este grupo de construcciones y las dadas intransitivamente mediante el grupo de predicativos introducidos por preposición vistas anteriormente, es obvia.

Los ejemplos con tener son interesantísimos. En principio siguen la línea de los casos vistos hasta ahora, es decir, predicativo obligatorio, algún tipo de desemantización, y ausencia de predicación secundaria. Tener puede tomar como complemento un predicativo cuyo sujeto establece necesariamente una relación de posesión con el sujeto de la oración principal, indicando el predicativo una propiedad, cualidad o estado de ese elemento poseído (aunque a veces puede ser necesario explicar con detenimiento dicha relación de posesión: tenemos a Juan enfermo, la niña nos tiene preocupados a todos). La construcción Juan tenía las manos sucias no implica Juan tenía las manos. Evidentemente hay un contenido posesivo implicado, pero Juan tenía las manos sucias no supone Juan tenía las manos y las manos estaban sucias, sino, simplemente, que las manos de Juan estaban sucias. Es una predicación no secundaria la implicada. Ahora bien, ¿en qué medida el significado de posesión del verbo tener ha sufrido algún tipo de cambio pasando a significar existencia o estado?5 $\mathrm{Y}$ planteo el problema sin considerar una posible

\footnotetext{
${ }^{5}$ Según Langacker (2004: 113), en los predicados tipo tener, hay un camino evolutivo que partiría de verbos agentivos que describen control inmediato físico, es decir, que representan acciones específicas. Desde aquí, habría un cambio semántico que resultaría en una predicación posesiva prototípica que afectaría a la atenuación en el grado de control agentivo respecto de varios parámetros: a) un predicado posesivo no designa una acción específica, sino más bien el potencial para interactuar con el objeto deseado (tener un coche no implica estar usándolo, sino sólo que puede hacerlo). b) El control del poseedor, cuando se ejerce, no se limita a la interacción física, sino que se extiende a situaciones abstractas (posesión abstracta), en las que los factores sociales y experienciales pueden ser más importantes que los físicos. c) Hay una atenuación en el carácter de controlador activo del poseedor: en casos
} 
predicación del tipo Juan posee manos y las manos están sucias, pues entiendo que la única predicación de la construcción dada es que las manos de Juan estaban sucias, pero la relación de posesión entre manos y Juan es expresada mediante la construcción con tener y un elemento poseído que es entendido como inalienable. Las relaciones entre posesión y existencia (y localización) son un tema apasionanté: según Benveniste (1966: 199), el verbo tener puede concebirse como una versión contraria del verbo estar. Construcciones del tipo $X$ tener $Y$ corresponden a $Y$ estar en $X$. La diferencia residiría en el hecho de que con el verbo tener la expresión del poseedor ha pasado del estatuto de objeto de una preposición locativa a sujeto de la construcción, denotando la entidad sobre la cual la expresión se aserta. Este es un tema muy controvertido, pero, en cualquier caso, lo que es indudable es la relación existente entre posesión, existencia y localización, los términos de esta relación son otra cosa. La conclusión, por tanto, es que podemos seguir entendiendo estas construcciones como construcciones de atributo no copulativo.

\subsection{Predicativos en cláusulas mínimas}

El último grupo de predicativos seleccionados léxicamente establecido por Demonte y Masullo es el dado en construcciones transitivas complejas o con cláusulas mínimas 7 . Dentro de este conjunto, Demonte y Masullo establecen dos subtipos según la clase semántica de los verbos.

\subsubsection{Verbos causativos}

El primero de ellos es el de los verbos causativos, donde incluyen ejemplos con hacer, volver, poner y dejar en su variante causativa. Lo primero que nos llama la atención es que, según Demonte y Masullo (1999: 2507), no todos los verbos causativos seleccionan una cláusula mínima. Así, volver loco a alguien no corresponde a una proposición, sino que, según Demonte y Masullo, los verbos causativos tienen en ciertos

como Sherridan tiene los ojos marrones, el sujeto es una especie de experimentador, y en casos como su casa tiene cuatro dormitorios, el poseedor es completamente pasivo, teniendo sólo una función de punto de referencia.

${ }^{6}$ Vid. Cifuentes 2012 al respecto.

${ }^{7}$ En la tradición generativista se denominan cláusulas mínimas a aquellas estructuras como consideran a Paul orgulloso, en las que el adjetivo constituye el predicado y el supuesto CD desempeña el papel de sujeto de la cláusula. Son mínimas o reducidas por no tener verbo, y se consideran cláusulas por entenderlas con sujeto y predicado (Campos, 1999: 1539-1542). 
usos, un carácter de verbo soporte o cuasi auxiliar. El planteamiento es interesante, pero me parece demasiado complicado. En el ejemplo propuesto, el verbo volver funciona exactamente igual que los verbos pseudocopulativos intransitivos de cambio de estado y resultado, es decir, el predicativo es obligatorio, no hay predicación secundaria, y el verbo está desemantizado (de ahí la vinculación señalada por Demonte y Masullo, supongo, con los verbos soporte), por lo que podríamos concluir que se trata de un caso idéntico de atributo no copulativo, con la diferencia, obvia, de que en este tipo de construcciones, al ser transitivas, la base de atribución es el complemento directo.

De igual forma, Demonte y Masullo señalan que los verbos mantener y conservar (incluidos en este subgrupo) son causativos no porque impliquen el devenir de un determinado estado de cosas, sino porque implican que una entidad causa continúe un estado de cosas que ya se viene dando, lo que lleva a considerarlas variantes del verbo soporte tener comentado anteriormente. No obstante, en el caso del ejemplo propuesto con conservar: conservaron intactos los manuscritos con un proceso químico especial, podemos plantearnos la duda de si se trata, o no, de un predicativo obligatorio, pues la construcción sin el predicativo me parece totalmente válida. Otra cosa sería una construcción del tipo te conservas joven, donde no está implicada la construcción te conservas, fundamentalmente porque el verbo parece propiamente pseudocopulativo (así lo recoge también Demonte y Masullo, 1999: 2513). De hecho, la RAE (2009: 2857) califica a los verbos conservarse y, mantenerse, siempre en forma reflexiva, de pseudocopulativos, pero no dice nada de la variante conservar. No así para mantenerse, pues entiende que tanto el atributo de sujeto de mantenerse como el atributo de CD de mantener son atributos no copulativos al tratarse de verbos pseudocopulativos. Así pues, tanto para conservarse como para mantener / mantenerse, tampoco hay predicación secundaria ni cláusula mínima, y podemos mantener el mismo planteamiento que llevamos hecho hasta ahora: predicativo obligatorio, verbo desemantizado, y ausencia de predicación secundaria, es decir, una construcción con atributo no copulativo, propia de los verbos pseudocopulativos.

Dicho lo anterior, parece que el único verbo causativo del que se puede plantear sin dudas una cláusula mínima es hacer. En estos casos, la cláusula mínima expresaría un estado de cosas causado o provocado por el sujeto del verbo. Así, una construcción como nunca nadie me ha hecho tan feliz alternaría con nunca nadie ha hecho que sea tan feliz. La relación semántica entre tales construcciones es indudable. Ahora bien, en otras construcciones es más dudosa: el cocinero hizo filetes las pechugas de pollo > el cocinero hizo que las pechugas de pollo sean filetes. Evidentemente el primer ejemplo es distinto de este último, pues en aquel hay un cambio de estado psíquico, y en éste, físico. Ahora bien, puestos a hacer paráfrasis, también podríamos hacerlas con construcciones con el 
verbo convertir, que, como los propios Demonte y Masullo señalan, parecen formar parte de los causativos transitivos, pero que son distintos sintácticamente. Y si se pueden parafrasear con convertir, ¿por qué no pensar en una doble construcción, con CD y CRégimen antes que en una cláusula mínimas? Sea como sea, lo cierto es que estamos ante un predicativo obligatorio, que no hay predicación secundaria, y el verbo tiene un valor de cambio de estado, lo que hace que se predique una propiedad, cualidad o estado de una base de atribución, en este caso un CD, y que podamos entender que se trata de un atributo no copulativo.

Entiendo que en los verbos causativos no hay exactamente una cláusula mínima, sino un predicado múltiple: X Causa [Y ser/estar/llegar a ser/... Z]. El verbo causativo expresa tanto el valor causativo como el valor atributivo. Estos verbos son exactamente iguales a los verbos pseudocopulativos, con la diferencia de que los pseudocopulativos intransitivos son de causación interna (Y Causa [Y ser/ser/llegar a ser/...Z) y los pseudocopulativos transitivos son de causación externa. No se trata, por tanto, de una predicación secundaria: no hay dos predicaciones, es el mismo predicado el que tiene dos valores compuestos, dos valores que se dan integrados si la construcción es intransitiva, y dos valores que se dan con componentes separados si la construcción es transitiva. Se trata de verbos atributivos, más bien pseudocopulativos, por no indicar meramente la cópula sino valores aspectuales mucho más complejos que los dados con ser, por ejemplo, y verbos atributivos complejos porque no indican un estado, sino un cambio de estado. Al señalar ese cambio de estado, es necesario diferenciar un causante de dicho cambio. Si el causante del cambio es el propio elemento objeto del cambio, se trata de una causación interna, propia de los verbos pseudocopulativos intransitivos, y si el causante del cambio es distinto del elemento objeto del cambio, se trata de una causación externa, propia de los verbos pseudocopulativos transitivos. No hay necesidad de dar cuenta de una predicación secundaria, por tanto, sino que hay que considerar un verbo complejo compuesto tanto por un valor causativo como por un valor atributivo. Así pues, la vinculación entre los atributos no copulativos de los verbos causativos y los atributos no copulativos de los verbos pseudocopulativos es obvia. En ambos casos hay un cambio de estado, bien aplicado al sujeto, bien aplicado al CD.

\footnotetext{
8 Extrañamente, Demonte y Masullo consideran las construcciones como convertir el agua en vino propias de los verbos con dos argumentos que seleccionan un segundo complemento preposicional de significado específico (1999: 2507), mientras que construcciones como Marta se convirtió en la persona de confianza del jefe o el agua se convirtió en vino las entenderían (1999: 2514) predicativas obligatorias con verbos pseudocopulativos.
} 


\subsubsection{Verbos epistémicos, volitivos y de orientación prospectiva}

El último subgrupo de predicativos obligatorios a comentar es el dado en cláusulas mínimas con verbos epistémicos, volitivos y de orientación prospectiva. En este tipo de construcciones se considera que el complemento predicativo y el argumento que modifica conforman un constituyente clausal o cláusula mínima. El verbo selecciona como elemento obligatorio al predicativo, el cual, a su vez, establece una relación semántica con el sujeto. En un ejemplo como considerar inteligente a Juan, se entiende (Fernández Leborans, 1999: 2501) que el verbo selecciona como complemento un contenido proposicional, y no una entidad concreta, y en esa estructura (Juan inteligente) encontramos una cláusula mínima, en tanto se establece una relación de predicación sujetopredicado, sin las especificaciones de tiempo, modo y aspecto que se dan en una cláusula conjugada plena, y dicha cláusula configura un constituyente de la oración que tiene una interpretación proposicional o eventiva completa. La paráfrasis mediante oración subordinada conjugada corroboraría este análisis: considero que Juan es inteligente. De esta forma, Juan no sería un argumento del verbo considerar, sino del complemento predicativo inteligente. Además, como el verbo selecciona al complemento predicativo, podríamos decir que Juan es un argumento de considerar-inteligente, es decir, de un predicado complejo.

En estos casos sí parece factible considerar una predicación no verbal, y, por tanto, una predicación secundaria. Tal y como señalan Hernanz y Suñer (1999: 2527), la posibilidad de predicar una propiedad, un proceso o una acción de una determinada base no es exclusiva de los verbos conjugados. Un sujeto junto a su predicado no verbal puede generar una oración reducida o cláusula mínima, es decir, una entidad oracional, en el sentido de que contiene una predicación, si bien de carácter defectivo, puesto que no está asociada a los rasgos flexivos de un verbo conjugado. En el ejemplo anteriormente visto, considero inteligente a Juan, de Juan se predica que es inteligente, si bien no mediante una oración independiente, sino que la cláusula mínima depende de los rasgos de flexión asociados al predicado principal (considero), entendiéndose, por tanto, inteligente como un predicado secundario al ser subsidiario, desde un punto de vista sintáctico, del predicado primario considero.

Así pues, con este tipo de predicativos obligatorios, encontramos un eslabón en la cadena o continuo entre atributo y predicativo, pues hay una predicación secundaria, como en los predicativos adjuntos, pero distinta, pues en un caso como Pedro bebió la leche fría, al ser el predicativo opcional, está implicada la construcción Pedro bebió la leche, y junto a ello, se predica simultáneamente la noción de que la leche que Pedro bebió estaba fría. Por el contrario, en considero inteligente a Juan, al ser el predicativo 
obligatorio, no es correcta la implicación considero a Juan, sino que lo que hay es una relación sintáctica y semántica de dependencia de la predicación no verbal respecto del verbo considero. Evidentemente hay estrechas relaciones funcionales y formales entre predicativos descriptivos y este tipo de construcciones, pues funcionalmente ambas están orientadas hacia el participante y aportan una predicación parcialmente independiente acerca de un participante de la predicación principal, es decir, es raro que una predicación secundaria pueda ser seleccionada completamente independiente de la predicación principal (Himmelmann y Schultze, 2005: 24-25). Formalmente, las dos construcciones se encuentran, en español, con la misma constitución interna y la misma marcación morfológica. La diferencia dependerá, evidentemente, de la obligatoriedad o no de algunos elementos argumentales. Van der Auwera y Malchukov (2005: 406-410) caracterizan construcciones como las dadas con considerar como un tipo distinto de construcción predicativa (complementativa, la llaman ellos), pues si bien predicativos descriptivos y complementativos establecen un tipo de predicación secundaria, en las construcciones complementativas la predicación principal es de tal forma que el hablante considera una proposición, y es dentro de esa proposición que encontramos una predicación segunda. La diferencia principal con los predicativos descriptivos es que la entidad a la que la predicación segunda se aplica no es una entidad dentro de la predicación primaria: mientras yo es un argumento del predicado considerar en considero a Juan inteligente, Juan no es un argumento del predicado considerar, tal y como hemos visto anteriormente. La alternancia pasiva es una buena prueba de su diferenciación: Juan inteligente es considerado por mí es una construcción agramatical, sin embargo, en construcciones predicativas descriptivas, la alternancia pasiva podría ser válida: la leche fría es bebida por mí. Es por ello que Van der Auwera y Malchukov consideren a las construcciones complementativas como un paso intermedio entre predicativas y atributivas.

En Pedro bebió la leche fría tendríamos una predicación con una representación semejante a: Pedro bebió la leche [la leche estaba] fría. Hay una predicación no verbal inserta, secundaria a la predicación principal. En el caso de los predicativos obligatorios con cláusulas mínimas, su representación sería algo parecido a: Juan considera a Pedro [ser] inteligente. Se trata, en estos casos de una predicación secundaria algo diferente a la de los predicativos opcionales, fundamentalmente por ese mismo hecho en sí: en los predicativos opcionales la predicación secundaria es opcional, pues la construcción es válida sin el predicativo. En el caso de los predicativos obligatorios, la predicación secundaria es obligatoria, pues el verbo principal necesita la predicación secundaria no verbal. Un paso más allá es el de los verbos pseudocopulativos transitivos, en el que no hay exactamente predicación secundaria, pero sí un predicado compuesto, al integrar el 
verbo tanto el contenido 'causa' como el contenido 'atribución', así como los valores aspectuales correspondientes, seleccionando un elemento distinto para desarrollar la causa y para desarrollar la base de la atribución, en tanto que cambio de estado. En el caso de los verbos pseudocopulativos intransitivos, la predicación compuesta se presenta simplificada, pues el sujeto de la atribución es el mismo que el de la causación, podríamos entenderlo, pues, como una causación interna, no externa como en los transitivos, pero el proceso es el mismo, lo que explica la facilidad con que podemos encontrarnos con idéntico significado un mismo verbo en estructuras transitivas y en estructuras intransitivas. En el caso de los predicativos obligatorios dados con verbos soporte, así como los dados con los grupos de verbos pseudocopulativos restantes (verbos de movimiento desemantizados, auxiliares aspectuales, y verbos de percepción destransitivados), no hay predicación secundaria alguna, sino que se trata de predicaciones atributivas (o pseudoatributivas) en las que el predicativo es obligatorio y el verbo, al encontrarse desemantizado, funciona atributivamente, junto con los valores aspectuales que aporte, si bien en alguna ocasión resultará difícil dilucidar si el verbo está desemantizado, recategorizado atributivamente, por tanto, o funciona predicativamente con una predicación secundaria, al no poder determinar, con precisión, la obligatoriedad, o no, del predicativo, y, por ello, la desemantización del verbo.

Así pues, podríamos intentar mantener la diferencia terminológica entre los elementos considerados, que forman un continuo, evidentemente, distinguiendo entre los atributos copulativos, propios de los verbos copulativos, los atributos no copulativos, propios del conjunto de los verbos pseudocopulativos, donde el verbo está desemantizado y no hay predicación secundaria, los predicativos obligatorios, propios de los verbos pseudocopulativos epistémicos, volitivos y de orientación prospectiva, y los predicativos opcionales, dados con verbos en los que no hay cambio de significado y la predicación es secundaria. Evidentemente, los verbos con atributos copulativos, no copulativos y con predicativos obligatorios permiten también usos no atributivos. 


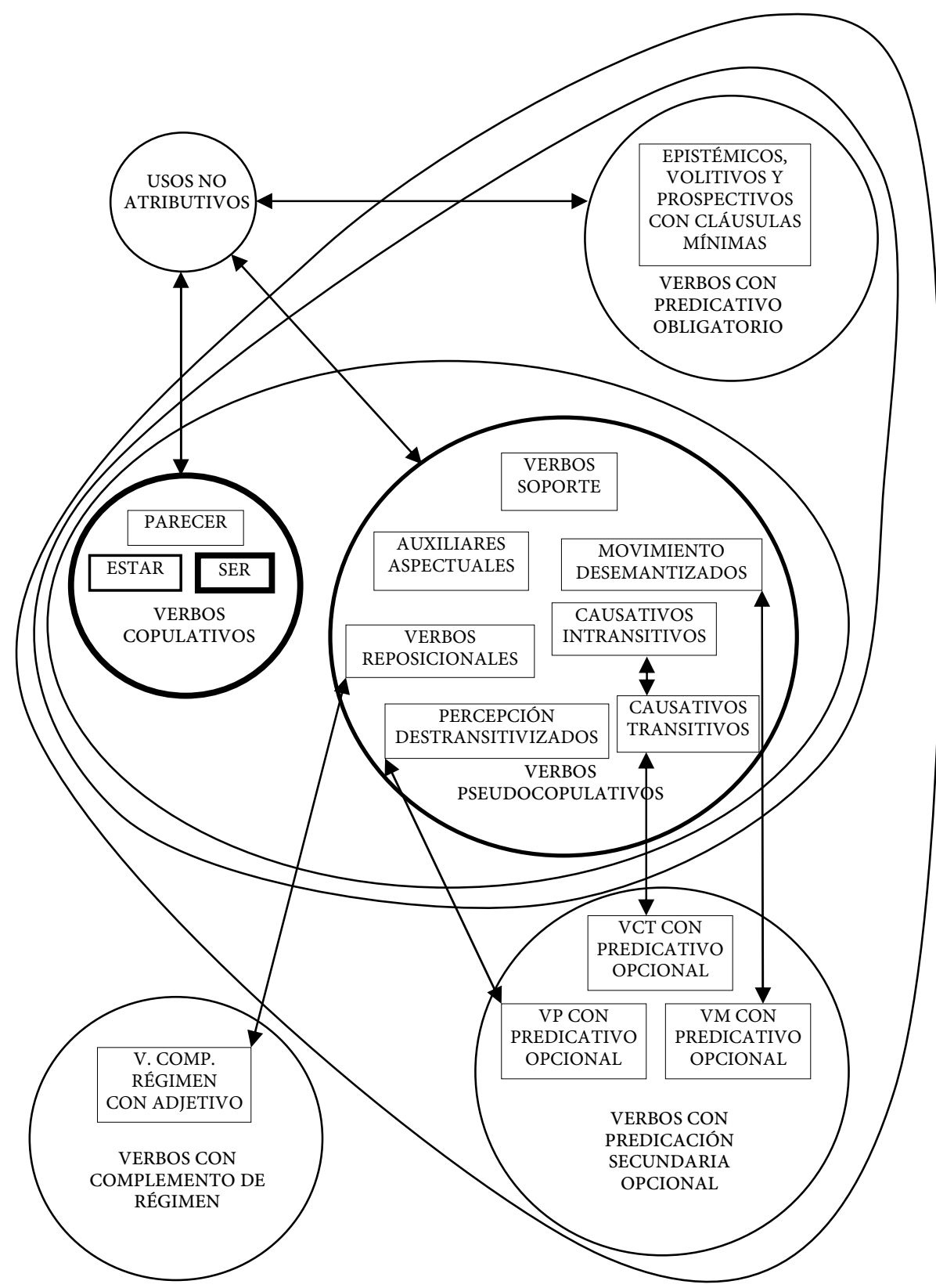




\subsection{Interpretación condicional}

La Gramática de la RAE establece (2009: 2873) que los predicativos de sujeto suelen ser opcionales, pues cuando son obligatorios nos encontramos con casos de verbos pseudocopulativos. Sin embargo, cuando los predicativos de sujeto denotan cierta condición la cosa parece cambiar. En efecto, con los verbos de volición encontramos un análisis similar al establecido para considerar, es decir, la implicación de una cláusula mínima. Una oración como quiero el tanque lleno no implica quiero el tanque, y ello aunque la construcción quiero el tanque sea válida, pero el estado de cosas significado en ambos casos es diferente. Si el predicativo se omite, se obtiene una oración gramatical, pero no se mantiene, sin embargo, el valor de verdad de la oración primitiva, ya que el predicativo denota un estado de cosas hipotético: no me gusta el té azucarado no implica no me gusta el té. El verbo selecciona una única unidad semántica que expresa un evento (a pesar de que sean legítimas construcciones sin el predicativo), por ello que sean posibles paráfrasis como no me gusta que el té esté azucarado, o quiero que el tanque esté lleno. Debemos considerar que algunos verbos de volición exigen que el tiempo del acontecimiento de la oración subordinada sea posterior al tiempo del acontecimiento de la oración principal (Carrasco Gutiérrez, 1999: 3084). Y ello es así porque el modo subjuntivo es obligatorio en las subordinadas con verbos de significado volitivo, introduciendo los predicados volitivos una modalización deóntica de la proposición subordinada, y no vinculando la verdad de la proposición sobre la que recae el deseo. Así pues, aunque la construcción no me gusta el té esté completa y no necesite más argumentos, no por ello supone un predicativo opcional en caso de que aparezca (no me gusta el té azucarado), sino obligatorio en alguna manera, pues si bien el verbo mantiene el mismo significado, hay implicada condicionalmente una predicación no verbal, lo que hace que el predicativo sea obligatorio de alguna manera. Demonte y Masullo señalan (1999: 2485) que estas construcciones parecen estar a medio camino entre la predicación adjunta y la léxicamente exigida, si bien más adelante (1999: 2505) parecen considerarlos exigidos. En cualquier caso, lo interesante, de nuevo, es el continuo entre atributo copulativo, atributo no copulativo, predicativo obligatorio y predicativo adjunto.

Hasta ahora siempre hemos estado hablando de predicativos descriptivos, pero hay que considerar que los predicativos en español pueden tener varias interpretaciones, aunque la descriptiva sea la más habitual. Según la RAE (2009: 2865, 2879-2884), son cuatro los valores semánticos de los predicativos y atributos no copulativos: a) interpretación descriptiva, en la que el predicativo encuadra, enmarca o reproduce cierta situa- 
ción temporal en la que se halla el elemento del que se realiza la predicación cuando lo afecta la acción o el proceso verbal, como ocurre con cualquiera de los ejemplos vistos hasta el momento. b) Interpretación causal: con algunos predicativos referidos al sujeto, se denota la causa de la acción o del proceso que se expresa. Por ejemplo, escapó descal$z a$ no es lo mismo que escapó presa del pánico, pues el primero expresa simultaneidad y el segundo causa. No obstante, tanto descriptivos como causales manifiestan el mismo comportamiento en las relaciones de implicación: escapó descalza implica escapó, y escapó presa del pánico implica escapó. c) Interpretación condicional: ciertos predicativos suponen no exactamente una propiedad, cualidad o estado de la base de atribución, sino un requisito que debe cumplir. Son los casos que hemos estado viendo con los verbos de volición: no me gusta el café azucarado no implica no me gusta el café, sino no me gusta el café si y solo si está azucarado. d) Interpretación resultativa, la cual pone de manifiesto un estado final alcanzado por el sujeto o el objeto como efecto de la acción o el proceso denotados por el verbo: la hierba crece alta, donde el predicativo se interpreta referido al estado en el que se encuentra lo designado por el sujeto al término de la acción.

Es claro que descriptivos y condicionales son morfológicamente idénticos en español, de forma que los dos tipos de predicativos están estrechamente relacionados, aunque se entienden como construcciones distintas en inglés debido a su interacción con el foco, pero en español son la misma construcción formalmente (Himmelmann y Schultze, 2005: 15-19). La distinción entre descriptivos y condicionales tiene una cierta tradición (Halliday, 1966: 78-81), sin embargo, el propio Halliday señala que la distinción parece algo arbitraria. Por ejemplo, en muchos casos va a depender de la aparición de un elemento modal en la predicación principal: puedo llevarlo vacío. En inglés, los predicativos secundarios condicionales han sido considerados un tipo distinto de predicación secundaria (con muy pocas excepciones, Nichols, 1978: 117; 1981; Plank, 1985: 169-170; Simpson, 2005). La diferenciación parece venir del hecho de que, semánticamente, en los descriptivos la relación lógica entre predicación principal y secundaria es exclusivamente de superposición temporal: el estado referido por el descriptivo es verdadero al mismo tiempo que el evento expresado por el predicado principal. En el caso de los condicionales, se evocan otros lazos semánticos además de la mera superposición temporal: condición y concesión, por ejemplo. Debido a la posible arbitrariedad de la distinción (tal y como señaló Halliday), es importante acentuar las diferencias formales entre las construcciones, unas diferencias formales posibles en inglés, por ejemplo, al ser los descriptivos parte del dominio de foco y aportar información focal, a diferencia de los condicionales, lo que se traduce en diferencias posicionales y prosódicas. Pero si ya en inglés, a pesar de las diferencias comentadas, Himmelmann y Schultze (2005) 
consideran a descriptivos y condicionales como pertenecientes a una clase general de descriptivos, siendo propiamente descriptivos los primeros, en español, que no hay diferencia formal, podemos englobarlos dentro de la misma clase a pesar de la diferencia semántica en la interpretación.

\section{Descriptivos y resultativos}

Es obvio que en español la gran oposición es entre predicativos descriptivos y resultativos, pues la interpretación causal y condicional puede considerarse variante de la descriptiva. Tipológicamente es la gran oposición establecida dentro de los predicativos.

Resultativos y descriptivos tienen en común su consideración como predicados secundarios: el estado codificado por la predicación secundaria se interpreta afectando a uno de los participantes de la predicación principal (el controlador). Pero mientras los descriptivos expresan un estado que se produce durante el tiempo de referencia del evento codificado por el predicado principal, los resultativos expresan un estado que es interpretado como resultado de un estado de acontecimiento codificado por el predicado principal (Himmelmann y Schulze, 2005: 4).

Las construcciones con predicativo resultativo en español son escasas (Demonte y Masullo, 1999: 2492), y se suelen ejemplificar con casos como Pedro pintó la casa verde, donde el predicativo describe el resultado causado por el proceso verbal. Demonte y Masullo (1999: 2492-2493) también comentan otras construcciones que califican de 'pseudorresultativas', como el tomate se pica bien finito, donde entienden que al no implicar causalidad no permite considerarlas resultativas en sentido estricto, pues no se significa que algo se pica hasta que quede fino, sino que ese estado es una variante del estado de 'estar picado'. La segunda construcción pseudorresultativa sería un ejemplo como haz la carne muy hecha, es decir, se trataría de un predicativo cognado que simplemente reitera el estado final del estado expresado a través del objeto directo. No obstante, Gumiel (2005: 44-45) considera que todas las construcciones son pseudorresultativas, incluidas las dadas en casos como Pedro pintó la casa verde, pues entiende que no son similares a las construcciones propiamente resultativas de lenguas germánicas (Mary pounded the metal flat 'Mary golpeó el metal y lo dejó plano'), pues mientras los predicados resultativos de lenguas como el inglés se construyen con verbos que denotan eventos que no están delimitados y les añaden un resultado, los predicados pseudorresultativos del español se construyen con verbos que ya están delimitados, y la aparición del predicado secundario supone hacer referencia a ese estado final, pero sin la adición de un resultado, puesto que la acción ya está acabada en el evento que expresa el verbo. En cualquier caso, interpretaciones descriptivas y resultativas son diferentes. 


\section{Descriptivos y construcciones absolutas}

Otro tipo de construcciones ligadas con los predicativos descriptivos son las construcciones absolutas. Coinciden todas en el hecho de constituir una predicación no verbal. Ahora bien, son construcciones claramente diferentes. Así, una construcción absoluta como muerto el perro, se acabó la rabia, expresa una predicación no verbal, desligada sintáctica y prosódicamente de la oración principal, aportando un significado semejante al de una subordinada adverbial. Las propiedades básicas que las caracterizan son las siguientes (Hernanz y Suñer, 1999: 2542): a) no son seleccionadas por el predicado principal (se acabó); b) poseen un sujeto explícito, pospuesto al predicado, que puede ser correferente o no con algún $\mathrm{SN}$ de la oración principal (no hay correferencia en el ejemplo propuesto); c) se organizan en torno a una heterogénea clase de predicados: participios, gerundios, adjetivos, adverbios y sintagmas preposicionales; d) la significación que aportan es básicamente temporal, pero también pueden añadir otros valores (causales, condicionales, etc.).

La diferencia fundamental entre las construcciones absolutas y las construcciones predicativas consideradas radica en que, a pesar de su coincidencia por tratarse de una predicación no verbal, esta predicación no verbal no se apoya en un verbo copulativo (como en las estructuras atributivas (copulativas o no copulativas), y tampoco tiene un comportamiento como predicación secundaria, al no encontrar en un predicado primario en forma de verbo conjugado el antecedente que permita su interpretación (Hernanz y Suñer, 1999: 2529). Este hecho de no constituir una predicación secundaria es el elemento clave para su diferenciación (Himmelmann y Schultze, 2005: 22). Evidentemente tienen que estar siempre vinculadas semánticamente con el texto en el que se insertan, si bien el tipo particular de relación depende de factores semánticos y pragmáticos (RAE, 2009: 2903): en el caso propuesto, es obvio que hay una vinculación entre perro y rabia.

Un problema añadido lo constituyen las construcciones incidentales, también denominadas adjuntos libres, como detenido e interrogado, negó tener conocimiento de los hechos que se le imputaban. Hernanz y Suñer las consideran diferentes de las construcciones absolutas (1999: 2546), siendo su principal diferencia en que carecen de sujeto explícito (y diferenciándose de las predicaciones descriptivas por las mismas razones que las construcciones absolutas, es decir, fundamentalmente por no constituir una predicación secundaria). No obstante, la RAE (2009: 2896 y ss.) recuerda la polémica que suscita considerar estas construcciones como provistas de un sujeto tácito, lo que las haría equivaler a las construcciones absolutas vistas: una vez publicado el libro, nos pareció mucho más breve / una vez publicado, nos pareció mucho más breve. 
Hay otro tipo de construcciones absolutas que están subordinadas a alguna otra categoría en el interior de un grupo sintáctico: esos sucesos tuvieron lugar bien entrado el mes de abril. En este caso no constituyen ningún inciso y son asimilables a un complemento circunstancial (RAE, 2009: 2906). Así pues, la RAE distingue tres tipos de construcciones absolutas: adjuntos libres (con sujeto o sin sujeto) ${ }^{9}$, integradas en la oración, como las anteriormente vistas, y las empleadas en enunciados independientes, denominadas por Hernanz y Suñer (1999) frases nominales, como, por ejemplo detenidos dos hermanos que vendieron dosis de droga mortales, o un hombre, un voto.

Dentro de las construcciones absolutas denominadas de adjunto libre con sujeto, son particularmente interesantes en español, por el valor adverbial que poseen y su vinculación con los mismos, un tipo de construcciones en las que un sujeto junto a su predicado no verbal pueden aparecer precedidos por la preposición con: nos escuchaba con los ojos cerrados. Como muy bien señalan Hernanz y Suñer (1999: 2548-2555), no se trata de simples sintagmas nominales encabezados por preposición, puesto que la elisión de los supuestos modificadores del núcleo nominal implican una construcción agramatical o con un significado diferente: nos escuchaba con los ojos. Evidentemente pueden aparecer otras preposiciones además de con, y, por otro lado, las construcciones absolutas así empleadas pueden desempeñar diversas funciones, además de circunstancial: atributo copulativo (está con el agua al cuello), atributo no copulativo (sigue con los ojos cerrados), predicativo de sujeto (pasó el río con el agua a la cintura), predicativo de $\mathrm{CD}$ (me devolvió el paraguas con una varilla rota) o complemento del nombre (la foto de Luis y María besándose ha causado sensación) (Hernanz y Suñer, 1999: 2550). Tal como ocurre con las construcciones absolutas, pueden desempeñar la función de predicado tanto participios como adjetivos, gerundios, adverbios y sintagmas preposicionales (1999: 2552). Así pues, y con los distintos tipos señalados, hacemos nuestra la definición de las construcciones absolutas dada por la RAE (2009: 2895): se trata de unidades de predicación no verbal, que suelen funcionar como predicados que aportan información adicional a la oración principal y se pronuncian con su propio grupo entonativo, si bien pueden también integrarse en la oración principal cuando están introducidas por preposición, e incluso como segmentos autónomos, como acabamos de ver. Se diferencian de las construcciones con predicativo descriptivo en que no suponen una predicación segunda respecto de una predicación principal, pero su vinculación con las mismas, y las estrechas relaciones que las unen, son obvias.

\footnotetext{
${ }^{9}$ Hernanz y Suñer (1999) las diferencian, distinguiendo las construcciones absolutas (con sujeto) de los adjuntos libres, entendidos carentes de sujeto explícito.
} 


\section{Predicativo y complemento de modo}

La diferencia entre predicativo y complemento de modo o manera parece haber quedado diluida en los últimos años. En la tradición gramatical (Cifuentes y Tornel, 1996) se ha insistido en el hecho de que el predicativo no incide únicamente en el sujeto de la oración, sino que al mismo tiempo parece afectar directamente al núcleo verbal, actuando como un complemento circunstancial de modo, y produciendo un índice elevado de ambigüedad en cuanto al discernimiento de una u otra función en una oración concreta, como en los siguientes ejemplos:

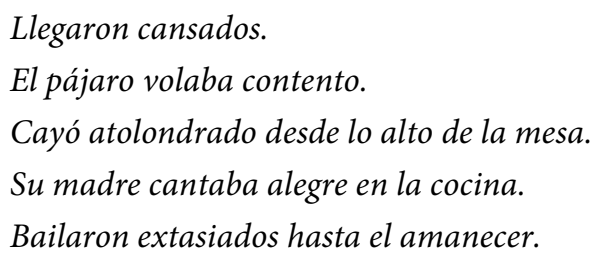

Es frecuente señalar que en todas las oraciones anteriores existe la doble posibilidad de escoger entre una incidencia del complemento adjetivo (cansados, contento, atolondrado, alegre, extasiados) sobre el sujeto (ellos, el pájaro, él, su madre, ellos), o sobre el contenido léxico expresado por el verbo (llegar, volar, caer, cantar, bailar). En el primer caso el complemento adjetivo sería un predicativo, mientras que en el segundo se trataría de un complemento circunstancial de modo.

Esta dualidad funcional es la que ha conducido a los investigadores a considerar estos complementos como situados a medio camino entre el atributo y el adjunto o complemento circunstancial: el predicativo incide tanto en el sujeto como en el verbo, mientras que el complemento circunstancial sólo incide en el verbo. La concordancia con el sujeto de los ejemplos anteriores sería una marca formal de la incidencia en el mismo.

\section{Predicativos preposicionales}

La consideración de que los sintagmas preposicionales alternan libremente con los adjetivos en la función de complemento predicativo (Demonte y Masullo, 1999: 2472) abre algunas inquietudes que conviene comentar.

Demonte y Masullo (1999) señalan que la posibilidad de aparecer como complementos predicativos no es exclusiva de una sola categoría, e indican que si la mayor parte de los predicados secundarios son adjetivos se debe a la naturaleza semántica de la construcción, pues la predicación secundaria caracteriza estados o propiedades de las expresiones nominales, por lo que es lógico que esta función la realice la categoría por 
antonomasia atribuidora de propiedades permanentes o transitorias. Tanto Demonte y Masullo (1999) como Gumiel (2005: 21-28; 2008: 174-177) admiten que no hay ninguna restricción sobre la categoría que puede aparecer como complemento predicativo, por lo que podemos encontrarnos en función de complemento predicativo: a) sintagmas nominales (Isabel resultó la mejor persona), b) sintagmas preposicionales (compramos el pollo sin piel), c) adjetivos (quiero las gafas obscurecidas), d) ciertas subordinadas, en determinados contextos, también pueden funcionar como predicativo (pintó a la niña que era una monada), e) un grupo restringido de adverbios, fundamentalmente bien, mal y algunos adverbios en -mente derivados de adjetivos evaluativos (Juan se sentía bien/estupendamente/estupendo), f) los participios de pasado alternan con los adjetivos y pueden aparecer en las mismas construcciones que estos, por tanto, pueden funcionar indiferentemente como predicativos (Inés se casó enamorada), g) los gerundios que expresan acciones pueden aparecer como complementos predicativos (María recitó el poema temblando).

Demonte y Masullo (1999) consideran que en ejemplos como la máquina carga los paquetes en grupos de tres o encontraron a Luis de mal humor, las preposiciones que introducen los complementos predicativos convierten una expresión referencial (un nombre) en una expresión de propiedad o estado. Así pues, los sintagmas preposicionales pueden funcionar como complementos predicativos, y, en la mayoría de estos casos, los sintagmas preposicionales alternan con sintagmas adjetivos. Ahora bien, los predicativos encabezados por preposición (normalmente con, de o en) introducen adicionalmente otros sentidos, como, por ejemplo, compañía (vive con su madre), modo (entró con sigilo), o adición (prepara las sardinas con aceite de oliva). Así pues, los valores más habituales son modo, compañía e instrumento, junto con una más imprecisa relación de adición (1999: 2489-2491).

Por lo expuesto hasta ahora, parece evidente que hay una indudable relación entre predicativos y complementos circunstanciales, en tanto que pueden adoptar valores similares (modo, compañía e instrumento, por ejemplo), y sintácticamente son semejantes (grupos preposicionales y adverbiales). Y si la diferencia, no explícita, parece radicar en la alternancia con adjetivos, es una diferencia poco precisa, pues fui a mi casa y fui un poco borracho también alternan y no se consideran funciones iguales.

Gumiel Molina (2005: 74-76) dedica un apartado a tratar las diferencias entre los complementos predicativos y otros tipos de complementos. Pero, extrañamente, solo establece la diferenciación entre los predicativos y los adverbios en función de complemento circunstancial, dejando un vacío, por tanto, en las interferencias entre predicativos y circunstanciales dados con sintagmas preposicionales (si es que los admite). Fundamentalmente, la diferencia entre unos y otros radicaría en la consabida afección: el 
predicativo establecería una relación tanto con el verbo como con el sintagma nominal al que modifica, mientras que los adverbios establecerían una relación con el verbo, sin relación alguna con ningún elemento de la oración.

La Nueva Gramática de la Lengua Española de la RAE es bastante clara, pues parte de la idea de que los atributos pueden ser preposicionales y adverbiales. Ya Fernández Leborans (1999: 2375-2377) recoge la tradición (señalada por autores como Navas Ruiz y Moreno, 1984: 28) de que los atributos pueden ser sintagmas preposicionales, siendo de, con, sin, a y para las preposiciones introductoras características: Pedro es de buen corazón, y que contribuyen a expresar el carácter, comportamiento, rasgos físicos, morales, etc., del sujeto. No obstante, la Nueva Gramática es mucho más clara al respecto, y establece la siguiente tipología:

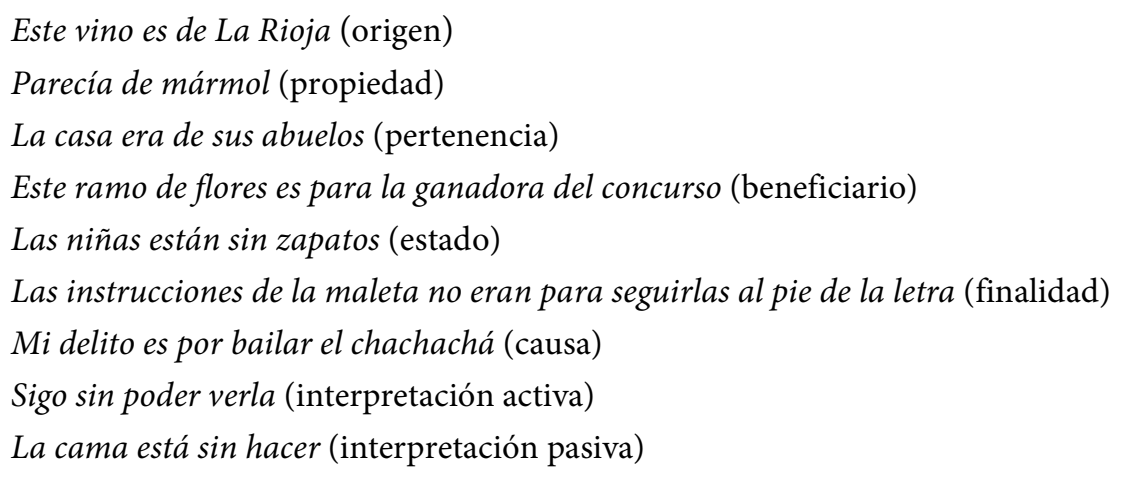

Añade también la posibilidad de aparición de locuciones adjetivas usadas como atributos (estoy de vacaciones, sigues de mal humor), así como relativas adverbiales sin antecedente expreso (lo encontré como me lo imaginaba) y ciertos adverbios que alternan con adjetivos, fundamentalmente algunos adverbios de valor ponderativo (te veo estupendamente, la fiesta estuvo muy bien). No parece haber acuerdo, según la RAE, con los grupos preposicionales locales (espaciales y temporales), pues plantea que unos autores los tratan como expresiones predicativas en oraciones copulativas, y otros como complementos locales seleccionados argumentalmente (está en Madrid, estamos en primave$r a)$. En definitiva, la relación entre localización y atribución es algo común en el conjunto de las lenguas (Cifuentes Honrubia, 2012).

Con estos antecedentes, no es de extrañar que la RAE sea bastante clara, por tanto, en la admisión de predicativos preposicionales como un tipo de atributo no copulativo (2009: 2885 y ss.), pudiendo funcionar los sintagmas preposicionales como complementos predicativos de sujeto (llegué con la lengua fuera) o de objeto directo, y ello tanto si son omisibles (la recuerdo con una pañoleta al cuello) como si son obligatorios (te veo con un zamuro de prendedor en el pescuezo), es decir, los grupos preposicionales pueden 

como «brusco», por lo que el adverbio se predica del proceso. En el segundo caso, el 
adverbio tiene como alcance a todo el evento, por lo que se trata de un adverbio que modifica tanto la acción que denota el verbo como al sujeto que la realiza. Es decir, al igual que ocurría con los predicativos, típicos complementos circunstanciales de modo o manera, como son los adverbios en -mente, pueden tener una doble incidencia: sobre el predicado verbal, o sobre el sujeto y el predicado verbal. A partir de aquí, Rodríguez Ramalle (2001: 133-139) admite la posibilidad de adverbios de manera orientados al sujeto, siendo predicados tanto de la actividad como del agente que realiza dicha actividad, y señala algunos datos a favor de esa caracterización: a) los adverbios predicados hacia el sujeto no pueden acompañar a verbos de $\operatorname{logro}^{10}$; b) los adverbios de manera orientados al sujeto proceden de adjetivos que se predican tanto de las acciones que realizan los individuos como de los propios agentes que las llevan a cabo ${ }^{11}$; c) los adverbios de manera verbal no pueden situarse en posición preverbal, sin embargo, los adverbios de manera orientados al sujeto ofrecen menores restricciones a dicha posición ${ }^{12}$; d) los adverbios orientados al sujeto se generan en una posición en la que mandan-c al argumento externo y a la acción verbal, es decir, por encima de la categoría Sv, en cuyo especificador se ha proyectado el argumento externo ${ }^{13}$.

Así pues, y aunque el trabajo de Rodríguez Ramalle solo viene referido a adverbios de manera orientados a una base en función sintáctica de sujeto (no de CD), lo significativo de su trabajo es el reconocimiento de que un típico complemento circunstancial de modo o manera, como es un adverbio en -mente, puede incidir sobre el sujeto, y no sólo sobre el evento verbal, con lo que la diferencia funcional con los predicativos queda bastante diluida, lo que legitimaría la afirmación de Bosque (1996) de la estrecha rela-

\footnotetext{
$10 *$ Pedro murió cuidadosamente / ${ }^{*}$ Los niños llegaron torpemente.

${ }^{11}$ Rápido / hábil / cuidadoso.

[estructura de evento $=\left[\mathrm{e}_{1}=\right.$ proceso $\left.]\right]$

[estructura de qualia $=\left[\right.$ formal $=$ 'es una cualidad $\left.\left.\left(\mathrm{e}_{1}, \mathrm{x}\right)\right]\right]$

Adjetivos como rápido, hábil, cuidadoso denotan cualidades de las acciones (e) en relación con los individuos que las realizan $(x)$. De esta forma, la estructura de los adjetivos anteriores recoge la posibilidad de que se prediquen tanto de las acciones como de los individuos, permitiendo la formación no sólo de adverbios de manera orientados hacia la actividad, sino también de adverbios de manera orientados al sujeto.

12 Adverbios de manera orientados al sujeto: Juan cuidadosamente ordena los libros / Pedro gentilmente ayudó a María / María torpemente derramó el café.

Adverbios de manera verbal: ${ }^{\star} J u a n$ perfectamente aprendió inglés / ${ }^{\star}$ Luisa estupendamente cocina / ${ }^{*}$ María fragmentariamente oye la radio.

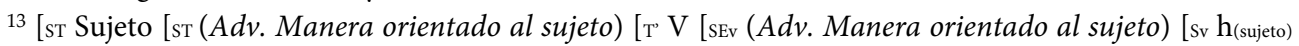
[ $v^{\prime}$ CAUSA/ACTIVIDAD]]]]]]].
} 
ción entre la predicación secundaria y la modificación adverbial, y su posible categoría funcional única. Es decir, y en palabras de De Miguel y Fernández Lagunilla (2004: 29), las relaciones entre predicación secundaria y modificación adverbial son muy variadas y aparentemente heterogéneas dependiendo del tipo de verbo.

Según De Miguel y Fernández Lagunilla, tanto la predicación secundaria como la modificación adverbial de manera son fenómenos que inciden sobre la estructura de un evento. Cuando se trata de una modificación adverbial, dicho complemento aporta información bien sobre cómo ocurre el evento en su totalidad bien sobre cómo se desarrollan las distintas fases de la estructura interna del evento (inicio, desarrollo y final). Cuando se trata de un predicado secundario, informa del estado en que se encuentra el sujeto en una determinada fase del evento denotado por el predicado primario ${ }^{14}$. Desde el momento en que las autoras reconocen que la modificación adverbial puede incidir sobre el evento en su totalidad, admitimos también la hipótesis de Rodríguez Ramalle de que si el adverbio tiene alcance sobre todo el evento, modifica tanto la acción denotada por el verbo como al sujeto que la realiza.

Así pues, está claro que predicativo y complemento circunstancial de modo o manera están vinculados. Y también está claro que una diferencia entre los mismos a partir de la incidencia sobre el sujeto o sobre predicado verbal va a ser poco concluyente, pues tanto unos como otros tendrán la doble posibilidad.

\section{Gramática catalana}

La situación en catalán es similar al español: López y Morant (2002: 1811) señalan la proximidad de los adverbios con los predicativos, a los que califican de quasiadverbis sintàctics $i$ semàntics, y precisan que resulta muy difícil diferenciarlos, pues pueden ejercer la misma función de predicado secundario y significan lo mismo, llegándolos a caracterizar como complements adjunts qualificatius, con la diferencia de que el adjetivo predicativo tiene concordancia. No obstante, la idea de manera es el fundamento de la predicación secundaria que los caracteriza, que comparten, evidentemente, con otros elementos. El esquema siguiente (2002: 1814) sintetiza bien los límites difusos e interferencias entre los mismos, significando el círculo A el valor semántico de manera, el

\footnotetext{
${ }^{14}$ La idea de que la predicación secundaria conecta estados del sujeto con fases del evento coincide con la caracterización tradicional del complemento predicativo como un modificador simultáneo del sujeto o del objeto y del verbo principal.
} 
círculo B el valor sintáctico de complemento circunstancial, y el círculo C el valor formal de palabra invariable:

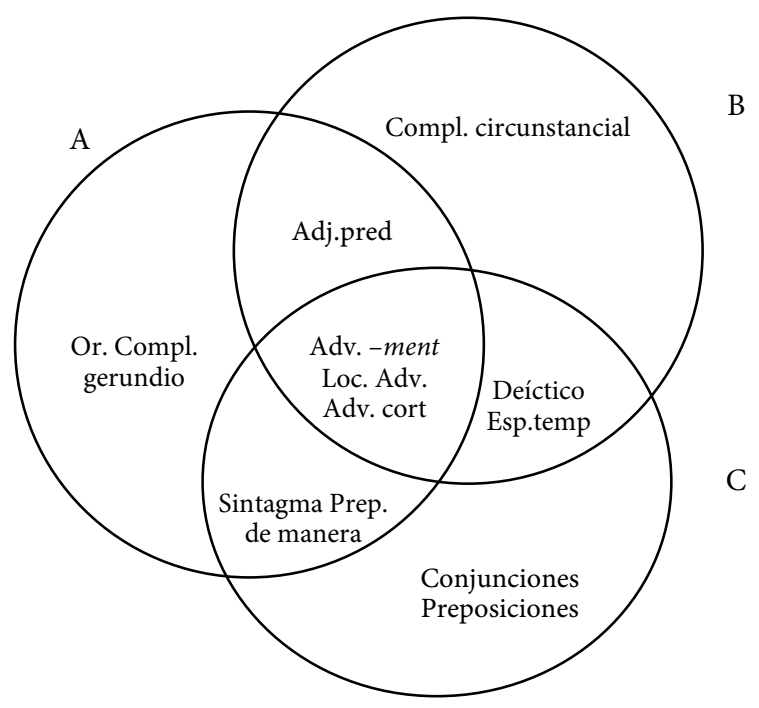

Ramos (2002: 1962) establece, también para el catalán, que el atributo puede ser un sintagma preposicional, y entiende que, tradicionalmente, se han distinguido atributos de complementos de manera o modales porque los primeros indican, desde un punto de vista semántico, propiedades, mientras que los complementos de manera indican estados (transitorios o finales), sin embargo, él los considera todos bajo el prisma del atributo (aunque distingue el atributo del predicativo), llegando a considerar tres tipos de atributos preposicionales y adverbiales: a) con SSPP introducidos por preposiciones de origen locativo, b) con SSPP constituidos por preposiciones como amb, sense, de, com (a), c) con SADVs y oraciones subordinadas de manera.

Así las cosas, no es de extrañar que Rigau (2002: 2049, 2091) exprese también las similitudes entre los predicativos y la mayoría de los complementos de manera, al predicar tanto unos como otros una cualidad de uno de los argumentos del predicado, $y$, al igual que López y Morant (2002), entiende que los dos son predicados secundarios que añaden una predicación generalmente calificativa a la predicación principal. Rigau llega a señalar explícitamente (2002: 2105) que cuando se trata de predicativos preposicionales, e incluso adverbiales, la frontera entre estos y los adjuntos de manera es borrosa, y entiende que los elementos que provocan más dificultades de análisis son los predicati- 
vos de sujeto y los complementos de manera agentivos: Passeja tranquil (P) / Passeja tranquil.lament $(\mathrm{CM}) /$ passeja amb tranquil.litat $(\mathrm{CM})$. Rigau plantea que la diferencia entre unos y otros radica en que, en el caso del adjunto de manera, éste incide en el evento verbal, pues SADV y SPrep se adjuntan al predicado para modificarlo expresando la cualidad de tranquil, es decir, lo que es tranquilo es el passejar, y queda implicado por este hecho que el sujeto esté también tranquil. En cambio, cuando se trata de un predicativo adjetivo, la incidencia es sobre el sujeto, pudiéndose dar, incluso, que el pasear no fuese tranquilo.

Así pues, la conclusión que obtenemos tras el breve repaso a una lengua hermana del español como es el catalán, es que: a) predicativo y adjunto de manera parecen diferenciarse por la incidencia: bien en el sujeto, bien en el evento; b) sus fronteras están totalmente borrosas, c) no hay una postura clara sobre su diferenciación.

\subsection{Gramática francesa}

Tal y como señala Goes (2009: 88), en la gramática francesa hay una cierta tradición de vincular atributo / predicativo y circunstancial de manera. Así, ya en Golay (1959) se señala la vinculación entre los mismos, caracterizándolos como épithètes y residiendo su diferencia en la incidencia, nominal y verbal, respectivamente. De igual forma, Bonard (1971) comenta la dificultad de diferenciar el atributo del complemento de manera, y construcciones como les piaillements s'élèvent plus aigus, plus précipités, plus étranglés, se considerarán con complementos de manera si el verbo es pleno, y atributivas si el verbo es semicopulativo, es decir, está desemantizado. La mezcla llega a ser tal, que algunos autores expresan una doble posibilidad de análisis: como atributos en relación al sintagma nominal, y como adverbios en relación al verbo (Arrivé, Gadet, Galmiche, 1986: 38; Wagner y Pinchon, 1962: 148): il se relève sain et sauf.

Goes (2009: 92-95) establece un continuo semántico entre atributo de sujeto, predicativo de sujeto, predicativo de objeto, adjetivo invariable y complemento adverbial de manera.

En el esquema siguiente, los elementos señalados con (1) son claramente atributos y complementos adverbiales de manera, mientras que los señalados con (2) muestran interferencias entre atribución y manera. Esas mismas interferencias se pueden encontrar en el caso del predicativo de objeto, pues, evidentemente, la incidencia del adjetivo es sobre el objeto, pero el alcance puede afectar también al verbo y contribuir, por ello, a poder expresar contenidos de manera. 


\begin{tabular}{|c|c|c|}
\hline Función & Incidencia & Naturaleza \\
\hline Atributo de sujeto (1) & Sujeto & $\begin{array}{c}\text { Adjetivo } \\
\text { (Paul est sorti apaisé de mon bureau) }\end{array}$ \\
\hline Atributo de sujeto (2) & $\begin{array}{c}\text { Sujeto }+ \text { alcance }^{15} \text { sobre el } \\
\text { verbo }\end{array}$ & $\begin{array}{c}\text { Adjetivo } \\
\text { (Les élèves assistaient attentifs à l'expérience) }\end{array}$ \\
\hline $\begin{array}{l}\text { Complemento adverbial de } \\
\text { manera (2) }\end{array}$ & $\begin{array}{c}\text { Verbo }+ \text { alcance sobre el } \\
\text { sujeto }\end{array}$ & $\begin{array}{l}\text { Adverbio en -ment orientado hacia el sujeto } \\
\text { (Pierre écoute attentivement) }\end{array}$ \\
\hline $\begin{array}{l}\text { Complemento adverbial de } \\
\text { manera }(2)\end{array}$ & $\begin{array}{c}\text { Verbo }+ \text { alcance sobre el } \\
\text { sujeto }\end{array}$ & $\begin{array}{l}\text { Adjetivo invariable } \\
\text { (La neige tombe dru) }\end{array}$ \\
\hline $\begin{array}{l}\text { Complemento adverbial de } \\
\text { manera (1) }\end{array}$ & Verbo & (Il parle bas) \\
\hline $\begin{array}{l}\text { Complemento adverbial de } \\
\text { manera (1) }\end{array}$ & Verbo & $\begin{array}{l}\text { Adverbio en -ment de manera } \\
\text { (Il est parti rapidement) }\end{array}$ \\
\hline
\end{tabular}

Con estos planteamientos, no debe sorprender que muchos autores hayan relacionado los atributos y los complementos adverbiales de manera, y que, incluso, algunos autores los hayan identificado en una sola función. La conclusión, para Goes, es que si bien están estrechamente relacionados, es posible diferenciarlos mediante los conceptos de incidencia y alcance: en el caso del atributo, la incidencia del adjetivo señala que se trata de una construcción atributiva de predicación secundaria, pero su alcance puede afectar también al verbo y dar lugar a un efecto de sentido de tipo pragmático, es decir, a una interpretación adverbial. En el caso de los adverbios en -ment, se trata de un proceso inverso: algunos complementos adverbiales de manera, a la vez que inciden en el evento verbal, pueden tener alcance sobre el sujeto, o sobre el objeto, con lo que atribución y manera están nuevamente interrelacionadas.

\subsection{Gramática neerlandesa}

El caso del neerlandés es muy interesante para los ejemplos que comenta Goes, pues si bien los adjetivos en neerlandés toman una $-e$ de flexión cuando funcionan como epítetos, son invariables en función atributiva, por lo que no hay diferencia entre adjetivo y adverbio. La única diferencia entre el adjetivo empleado como adverbio y los "verdaderos adverbios", derivados de adjetivos o no, sería de orden sintáctico. Así, la Algemene Nederlandse Spraakkunst da ejemplos de "verdaderos adverbios" utilizados como adjetivos, y añade que es muy difícil delimitar con exactitud las dos subclases de adver-

${ }^{15}$ Con la idea de alcance quiere señalar la "referencia semántica", es decir, el elemento sobre el cual el adverbio señala preferentemente alguna cosa, frente a la incidencia, que es sintáctica. Así, por ejemplo, en ejemplos como (1) Jean travaille manuellement, (2) Jean travaille jovialement, (3) Jean travaille minutieusement, evidentemente la incidencia es sobre el evento verbal, pero el alcance es diferente: sobre el verbo en (1), sobre el sujeto en (2), y sobre sujeto y verbo en (3) (Goes, 2009: 93). 
bios: los adjetivos utilizados como adverbios y los verdaderos adverbios. Seguramente fueron planteamientos similares los que condujeron a De Groot (1948: 454) a señalar que, en neerlandés, adjetivos y adverbios constituyen una única clase de palabras.

Así pues, al no disponer el neerlandés más que de una sola forma, el adjetivo atributo morfológicamente nunca puede concordar, por lo que no puede distinguirse del adverbio, siendo su forma exactamente la misma, y, por ello, difícil de diferenciar el atributo de sujeto o el predicativo de objeto del complemento adverbial de manera con alcance en el sujeto / objeto. Semánticamente los matices significativos son los mismos, pero su interpretación queda totalmente a expensas del interlocutor y del contexto (Goes, 2009: 100-101).

\subsection{Predicación secundaria descriptiva y tipología lingüística}

En los apartados anteriores hemos comprobado cómo las interferencias entre predicativos y adjuntos no son exclusivas del español. El trabajo de Palancar y Alarcón (2007) considera nuevamente la relación entre predicativos y complementos circunstanciales, pero lo hace situándola en el marco tipológico de la semántica depictiva o descriptiva. Los autores establecen una distinción entre predicativos descriptivos adjetivales y predicativos descriptivos preposicionales, relegando estos últimos al campo de los "adjuntos generales", que si bien son predicativos y tienen contenido descriptivo, no se clasifican sintácticamente dentro de la propuesta como predicados secundarios descriptivos. Entienden los citados autores (2007: 363-363) que los sintagmas preposicionales no funcionan tipológicamente como predicativos descriptivos al no estar diferenciados morfosintácticamente, como sí lo están los sintagmas adjetivales, gracias a la concordancia.

Los citados autores siguen la tradición de distinguir entre la orientación hacia el participante, propia de la semántica de los predicativos descriptivos, y la orientación hacia el evento, propia de la semántica adverbial (2007: 343), si bien reconocen que hay elementos adverbiales que también pueden tener orientación al participante.

Así pues, parece interesante considerar las aportaciones que los estudios de tipología lingüística han efectuado sobre la predicación secundaria descriptiva, aun sin confundir la perspectiva tipológica con una perspectiva que pretende describir el uso en una lengua determinada, para analizar sus aportaciones al problema objeto de análisis.

A la hora de estudiar los predicativos descriptivos, hay algo claro tipológicamente, y son sus vinculaciones semánticas con otras nociones como atributos, adverbios y predicativos obligatorios, algo que ya hemos repasado anteriormente. 
Las construcciones descriptivas constituyen una predicación secundaria a la predicación principal, encontrándose dicha predicación secundaria fuera de la expresión referencial que identifica el participante de la predicación principal, y solapándose el intervalo temporal de la escena denotada por la predicación secundaria con la escena denotada por la predicación principal. La predicación secundaria normalmente dibuja un estado (fase o función) en el que el participante de la predicación principal se encuentra. Más concretamente, Schultze \& Himmelmann caracterizan tipológicamente la construcción con predicación secundaria descriptiva mediante los siguientes rasgos (2004: 77-78):

1) Contiene dos predicaciones separadas: el predicado principal y el descriptivo. La escena expresada por el descriptivo se produce dentro del marco temporal de la eventualidad expresada por el predicado principal.

2) El descriptivo está controlado de forma obligatoria, es decir, hay una relación formal con un participante de la predicación principal, el controlador, que no está expresado de forma independiente como un argumento del descriptivo.

3) El descriptivo hace una predicación sobre su controlador que es al menos en parte independiente de la predicación expresada por el predicado principal, es decir, el descriptivo no forma un predicado complejo o perifrástico con el predicado principal.

4) El descriptivo no es un argumento del predicado principal, es decir, no es obligatorio.

5) El descriptivo no es un constituyente inmediato del controlador, es decir, no funciona como un modificador de dicho controlador dentro de un Sintagma Nominal.

6) El descriptivo no está marcado con las categorías de modo o tiempo, indicándose la dependencia del descriptivo respecto del predicado principal mediante otros medios formales.

7) El descriptivo es parte de la misma unidad prosódica que el predicado principal.

Configurados de esta manera tipológicamente, es obvio que los predicativos descriptivos tendrán indudables afinidades semánticas con otras nociones semánticas y sintácticas, como atributos, adverbios, predicativos resultativos, predicativos obligatorios, circunstanciales y modificadores nominales (Van der Auwera \& Malchukov, 2005: 420), como ya hemos comentado anteriormente. Es más, Schultze \& Himmelmann (2007: 78) señalan que la construcción descriptiva es un subtipo de construcción adjunta o circunstancial, y que debe ser diferenciada de otras construcciones adjuntas a partir de rasgos formales. 
Desde el punto de vista tipológico, es más que correcto el planteamiento de Schulze y Himmelmann. No obstante, desde el punto de vista descriptivo de la lengua, es indudable que es necesario dar cuenta de las relaciones del predicativo descriptivo con otras unidades, relaciones que, en muchos casos, no van a suponer límites claros, sino fronteras difusas.

\section{Descriptivos y complementos circunstanciales}

Palancar y Alarcón (2007: 339) solo consideran predicativos descriptivos los que aparecen como sintagmas adjetivos (y en forma de gerundios). Los sintagmas preposicionales que tradicionalmente han sido incluidos dentro de la función predicativa descriptiva quedan relegados a adjuntos generales, que si bien se reconocen como predicativos, no los clasifican como predicados secundarios descriptivos. La razón de su diferenciación radica, fundamentalmente, en la concordancia en género y número que toman los adjetivos en función descriptiva en español, frente a la ausencia de concordancia de los sintagmas preposicionales.

Schultze y Himmelmann (2004: 78) consideran la construcción descriptiva un subtipo de una construcción adjunta general, y si, y solo si, el contenido descriptivo y el contenido adverbial son expresados mediante tipos de construcciones sintácticamente diferentes, será posible distinguir descriptivos de adverbios. En español sí es posible dicha diferenciación gracias a los predicativos descriptivos que muestran concordancia de género y número con su controlador, no así en los predicativos descriptivos preposicionales que, en principio, no se distinguirán ni formal ni semánticamente de los adverbios.

Si hay algo claro de los trabajos de Schultze y Himmelmann $(2004 ; 2005)$ es que descriptivos y adverbios tienen límites difusos. De hecho, si bien en español o inglés es posible diferenciar formalmente descriptivos y adverbios, en alemán o neerlandés no hay diferencia (2004: 61): la traducción alemana de George left the party angrily, Georg hat die Party wütend verlassen, permite tanto una lectura descriptiva (George was angry although his anger was not necessarily obvious in the manner of his departure) como una lectura adverbial (George left in an angry manner). Consideran que la superposición semántica y formal entre construcciones adverbiales y descriptivas (ejemplificada anteriormente) es parte de una superposición mucho más genérica entre las dos construcciones, pues hay lenguas que expresan típicos contenidos adverbiales (manera, localización, tiempo) mediante construcciones morfosintácticamente descriptivas, $y$, a su vez, hay lenguas que no parecen tener genuinas construcciones descriptivas, por lo que típicos contenidos descriptivos son expresados mediante diversas construcciones, inclu- 
yendo construcciones que expresan típicos contenidos adverbiales. Es decir, desde el punto de vista interlingüístico, construcciones adverbiales y construcciones descriptivas están en competencia, puesto que el mismo tipo de contenido puede ser expresado por una construcción descriptiva en unas lenguas y por una construcción adverbial en otras.

Semánticamente, la diferencia entre adverbios y descriptivos va a ser muy difícil de establecer con nitidez, pues va a establecerse en la dependencia u orientación (bien hacia el evento, bien hacia el controlador), pero hay lenguas, como el español, en las que se marca morfosintácticamente la relación (gracias a la concordancia). En lenguas como el español en las que hay una clara diferencia morfosintáctica es necesario distinguir dos tipos de construcciones diferentes, una adverbial y otra descriptiva, que difieren semántica y sintácticamente. Pero al igual que sería ingenuo, y falso, esperar que tal distinción entre los dos tipos de construcciones se diera en todas las lenguas, también es ingenuo esperar que dentro de una misma lengua no haya fronteras difusas entre las mismas. Es así como se explica, entonces, la afirmación anterior de Schultze y Himmelmann de que los dos tipos de construcciones son instancias de una construcción adjunta general, y que haya construcciones adjuntas que pueden tener tanto lecturas descriptivas como adverbiales. La construcción descriptiva, si lo es, debe estar diferenciada morfosintácticamente de la construcción adverbial. Semánticamente, la diferencia radica en la orientación hacia el participante por parte de la construcción descriptiva y la orientación hacia el evento por parte de la construcción adverbial. Evidentemente dicha diferenciación es gradual, más que discreta (Schultze y Himmelmann, 2004: 79):

\begin{tabular}{|l|l|l|l|c|}
\hline \multirow{2}{*}{$\begin{array}{l}\text { Nivel morfosin- } \\
\text { táctico }\end{array}$} & \multicolumn{3}{|c|}{ Construcción adjunta general } \\
\cline { 2 - 4 } & Construcción descriptiva & $\vdots$ & Construcción adverbial \\
\hline Nivel semántico & $\begin{array}{l}\text { Expresión orientada } \\
\text { hacia el participante }\end{array}$ & & $\begin{array}{l}\text { Expresión orientada } \\
\text { hacia el evento }\end{array}$ \\
\hline
\end{tabular}

La orientación hacia el participante suele considerarse el principal rasgo distinguidor de predicados secundarios frente a adverbios ${ }^{16}$, que se adscriben exclusivamente a la

\footnotetext{
${ }^{16}$ Evidentemente, como recuerdan Van der Auwera y Malchukov (2005: 411), el evento afecta a los participantes, de forma que lo que se predica de un evento pertenece igualmente a los participantes, por lo que la predicación de las propiedades de los eventos se relaciona con la predicación de las propiedades de los participantes. Ya dijimos que en la tradición gramatical española (Cifuentes y Tornel, 1996) se ha insistido en el hecho de que el predicativo no incide únicamente en el sujeto de la oración, sino que al mismo tiempo parece afectar directamente al núcleo verbal, lo cual es una traducción de la anterior consideración. Demonte y Masullo (1999: 2463) denominan predicativos a "aquellos constitu-
} 
orientación hacia el evento, sin embargo, uno u otro tipo de orientación no se alinea claramente con las construcciones descriptivas y adverbiales respectivamente (Himmelmann y Schultze, 2005: 4).

El hecho de que los adverbios no se orientan exclusivamente hacia el evento, sino que pueden mostrar una orientación semántica hacia un participante, tiene una gran tradición lingüística (Jackendoff, 1972; 47-107; Platt y Platt, 1972; Bartsch, 1976: 144; Dik et alii 1990: 31; McConell-Ginet, 1982; Quirk et alii 1985; Higginbotham, 1989; Wyner, 1998; Frey y Pittner, 1998: Eckardt, 1998; Ernst, 2000; Geuder, 2002; etc.). Una construcción como John respondió a la pregunta estúpidamente solo puede interpretarse con una orientación al evento, pues John respondió a la pregunta de forma estúpida. Ahora bien, si decimos estúpidamente John respondió a la pregunta, podríamos entender una orientación hacia el participante, al considerar que John fue un estúpido por responder a la pregunta. Parece, pues, que la orientación al participante describe la condición emocional del sujeto en el tiempo de respuesta, lo que supone una estrecha vinculación con los descriptivos, que también pueden significar algo parecido. La orientación al participante tiene que entenderse como orientación a un individuo, de forma que la perspectiva dada con adverbios como inteligentemente es preguntar en qué consideración su significado tiene que comprenderse sobre las bases de las propiedades de los individuos expresados por los adjetivos subyacentes.

Según Himmelmann y Schultze (2005: 9), la principal diferencia semántica entre descriptivos y adverbios orientados hacia el participante es debida a la relación establecida entre el estado de hechos denotado por el predicado principal y la condición denotada por el adjunto orientado hacia el participante. En el caso de los descriptivos, la relación es simplemente de superposición temporal, mientras que en el caso de los adverbios de este tipo tal relación va más allá de la mera coincidencia temporal y refleja una ligazón más profunda, a menudo referida a algún aspecto causal o motivador de la misma: John abandonó irritado la fiesta vs. irritadamente John abandonó la fiesta. No obstante, debemos recordar cómo muchos predicativos pueden tener interpretaciones causales o condicionales. En definitiva, adverbios y descriptivos son muy similares en al menos algunos de sus usos (Himmelmann y Schultze, 2005: 10), y las diferencias semánticas entre descriptivos y usos adverbiales orientados hacia el participante pueden ser muy sutiles y difíciles de explicitar, si bien formalmente tales diferencias existen, tanto en inglés como en español, ya que los descriptivos manifiestan concordancia y la

yentes que modifican simultáneamente al predicado verbal y a un sintagma nominal de la misma, con cuyo núcleo concuerdan". 
mayoría de los adverbios suponen el sufijo -mente. Y no tenemos que irnos al alemán o al neerlandés para demostrar una carencia de diferenciación morfológica entre un uso adverbial orientado hacia el participante y un uso predicativo descriptivo adjetival, lo que podría hacer cuestionable su diferenciación en general (no considero ahora los problemas relativos al orden de palabras), sino que, en español, en el caso de los sintagmas preposicionales, podríamos cuestionarnos la indiferencia, o no, de las funciones de predicado descriptivo y complemento circunstancial.

Suele señalarse como diagnóstico diferenciador entre descriptivos y adverbios las distintas paráfrasis permitidas (Himmelmann y Schultze, 2005: 11-12). Así, en el caso de los descriptivos, pero no para los adverbios, los descriptivos pueden parafrasearse mediante una oración subordinada en la que el elemento correspondiente al descriptivo funciona como un predicado primario: Jorge compró frescas las zanahorias > las zanahorias estaban frescas (cuando Jorge las compró). En el caso de las construcciones adverbiales, estas pueden parafrasearse mediante una cláusula en la que el elemento correspondiente al adverbio funciona como el predicado principal, o bien mediante una construcción atributiva en la que el elemento correspondiente al adverbio es un modificador de un nombre verbal: Jorge compró las zanahorias rápidamente: la compra de las zanahorias (por parte de Jorge) fue rápida / la rápida compra de las zanahorias (por parte de Jorge). Frente a *la compra de las zanahorias (por parte de Jorge) fue fresca(s) / *la fresca compra de las zanahorias (por parte de Jorge). Sin embargo, como señalan los autores comentados, incluso estos ejemplos utilizados para mostrar las supuestamente claras diferencias entre descriptivos orientados hacia el participante y adjuntos adverbiales orientados hacia el evento no son concluyentes, pues es posible parafrasear la construcción adverbial de forma similar a la descriptiva: Jorge fue rápido (cuando compró las zanahorias). Así pues, parece llevar razón Plank (1985) al señalar que la intuición semántica y las pruebas de paráfrasis no permiten distinguir entre un adjunto orientado hacia el participante y un adjunto orientado hacia el evento en ausencia de marcación formal, ya que parece que el mismo adjunto (como en el caso de rápidamente) puede ser construido tanto orientado al participante como orientado al evento. Además, desde una perspectiva interlingüística, una similitud entre descriptivos y adverbios en muchas lenguas, incluido el español, es que ambos pueden ser sustituidos por el interrogativo cómo en construcciones interrogativas. De igual forma, típicos adverbios orientados al evento, como rápidamente, son traducidos en muchas lenguas como descriptivos, incluso marcando concordancia con el controlador (Himmelmann y Schultze, 2005: 12-14), lo que sería una prueba más del continuo entre adverbios y descriptivos comentado anteriormente por Schultze y Himmelmann. 
Así las cosas, Himmelmann y Schultze (2005: 14-15) establecen la siguiente diferenciación: una construcción de predicado secundario descriptivo es una construcción fundamentalmente dedicada a expresar orientación hacia el participante, no obstante, ciertas expresiones que afectan a construcciones descriptivas probablemente tienen que ser consideradas como orientadas al evento en algunas lenguas. Frecuentemente, la orientación hacia el participante se ve reflejada icónicamente en la marcación formal de la construcción descriptiva (como ocurre en español), por ejemplo mediante la concordancia del descriptivo con su controlador. Es importante señalar que la construcción descriptiva diferirá en al menos un rasgo de otras construcciones adjuntas, como por ejemplo en su posición sintáctica o en el hecho de que la construcción es no marcada morfológicamente mientras que otras construcciones adjuntas son marcadas. Una construcción adverbial, por otro lado, es una construcción distintiva (marcada por una afijación adverbial o mediante una distinta posición) que se dedica fundamentalmente a expresar orientación hacia el evento, aunque en algunos casos puede interpretarse como orientada hacia el participante. Por último, una construcción adjunta general viene usada para aquellos adjuntos que son neutros con vistas a la distinta orientación hacia el evento o hacia el participante, permitiendo, por tanto, con una lectura no marcada cualquiera de las dos interpretaciones. La conclusión, pues, es que, en el caso del español, las construcciones descriptivas están marcadas a través de la concordancia, y las construcciones adverbiales también lo están, a través, fundamentalmente, de la morfología del sufijo -mente, o la invariabilidad de las formas adverbiales. En el caso de los sintagmas preposicionales y su dualidad de interpretación como predicativos o como complementos circunstanciales de manera, éstos parecen relegados, por su ausencia de distinción morfosintáctica, al grupo conjunto de adjuntos generales.

Tanto Demonte y Masullo (1999: 2473) como Gumiel (2005: 24-25)17 señalan que un conjunto restringido de adverbios (bien, mal y algunos adverbios en -mente) pueden funcionar como predicativos y como atributos, excluyendo la posibilidad de entenderlos como adverbios de modo o manera. Algo corroborado por la RAE (2009: 2790) al afirmar que las relativas adverbiales sin antecedente expreso funcionan asimismo como complementos predicativos: lo encontré como me lo imaginaba, y la posibilidad de entender los adverbios locales como expresiones predicativas. Pero lo más interesante es la consideración de que algunos adjetivos y adverbios pueden alternar en función de atributo, especialmente con ciertos adverbios de valor ponderativo: todo estaba estupendo / estupendamente, tanto con verbos copulativos como pseudocopulativos. Por otro la-do,

${ }^{17}$ Extrañamente no así en 2008. 
la RAE reconoce (2009: 2866-2867) la estrecha relación de los predicativos de sujeto con los adverbios orientados al sujeto: entró cauteloso / cautelosamente; pagaba puntual/puntualmente la renta. Los adverbios orientados al sujeto expresan una manera de actuar definida en función de alguna propiedad ('cautela', 'puntualidad', etc.) que se atribuye a la base de atribución y a la propia acción.

Como vemos, la consideración de los adverbios orientados a algún participante o controlador es habitual en la gramática española. O. Kovacci (1999: 728-733) distingue tres tipos de adverbios de modo o manera que pueden funcionar como circunstanciales facultativos: a) adverbios de acción y agente, construidos generalmente con verbos de acción y que tienen por función calificar la acción en su desarrollo (Alberto contemplaba atentamente los cuadros $>$ Alberto contemplaba los cuadros y lo hacía atentamente) y calificar al agente. b) Adverbios de acción, que se comportan como los de acción y agente, pero sus adjetivos correspondientes no se pueden aplicar al agente: la niña se puso dificultosamente en pie > la niña se puso en pie y lo hizo dificultosa(mente). c) Adverbios resultativos, que modifican verbos de acción, proceso o estado en cuanto a su cumplimiento total, de modo que califican este resultado. En ocasiones, el resultado puede relacionarse con un paciente, un experimentante o un complementante (una droga que curaba definitivamente el asma > cura definitiva del asma / el asma se cura definitivamente; hirieron gravemente al hombre > el hombre está grave; no sabe escribir completamente la palabra > no sabe escribir completa la palabra). Además de las tres clases señaladas, Kovacci incluye dentro de los adverbios de modo otros adverbios en -mente que a la vez que funcionan como circunstanciales de modo, expresan también otras acciones: causa (recibir hereditariamente / por herencia una cosa), instrumento (elaborar algo manualmente/con las manos) y medio (calcular mentalmente/con la mente).

La RAE (2009: 2341-2343) recoge también la clasificación anterior y diferencia los adverbios de manera orientados al sujeto, también llamados adverbios orientados al agente o adverbios agentivos, que presentan cierta propiedad de una acción, pero también de la persona o de la cosa designada en la situación concreta que se describe (lo saludó cortés / lo saludó cortésmente). La forma de actuar que se describe se atribuye a la persona o a la cosa designada por el agente. Distingue también un segundo grupo de adverbios de manera orientados al objeto, que indican la forma en que la acción afecta al complemento de algún predicado: lo hirieron mortalmente expresa, evidentemente, una manera de herir, pero su característica principal es que expresa cierto cambio de estado en el que recibió la herida, y no una situación del que la causó. El último grupo de adverbios es el de los adverbios de manera orientados a la acción, e incluye a aquellos que se refieren a ciertos obstáculos que la acción ha de salvar, o a otras circunstancias que la caracterizan de forma intrínseca: respiraba fatigosamente muestra una fatiga al respirar, 
pero la propiedad de ser fatigoso no se predica de las personas, sino de las acciones o de los procesos. Los límites entre adverbios orientados al sujeto y adverbios orientados a la acción son especialmente difusos cuando la propiedad que denota el adjetivo del que proceden se predica de las personas y también de las acciones: respondió violentamente.

La conclusión provisional que de momento podemos obtener es que hemos organizado un auténtico caos: parece que los adverbios orientados al participante (bien agente bien objeto) podrían ser semejantes a los descriptivos, y hay autores que los entienden con función atributiva o predicativa. No obstante, hay autores que parecen excluir la interpretación funcional atributiva o predicativa en los adverbios en -mente. Por otro lado, ¿todos los adverbios de manera orientados al participante podrían considerarse atributos o predicativos?, ¿y si ampliamos el cupo a los adverbios con valor de causa, instrumento y medio?

Tanto Demonte y Masullo como Gumiel parecen incluir únicamente a los adverbios en -mente derivados de adjetivos evaluativos como los capaces (junto con bien y mal) de funcionar como predicativos o atributos: estupendamente, maravillosamente, espléndidamente, etc. No obstante, si eso es así, ¿por qué estos adverbios en -mente son distintos del resto de adverbios en -mente orientados al participante?, ¿acaso tienen el mismo significado se la veía maravillosamente ${ }^{18}$ y se la veía maravillosa?, ¿tiene algo que ver el hecho de que todos estos adverbios parecen poder combinarse funcionalmente como modificadores de los adverbios bien o mal (se la veía maravillosamente bien)?, ¿podría entenderse algún proceso de elipsis o de gramaticalización referente a la ausencia del adverbio bien (o $\mathrm{mal}$ ) como base de la aceptación de las construcciones con este tipo de adverbios en -mente?

\section{Sintagmas preposicionales orientados al participante}

Ya hemos señalado anteriormente que tanto Demonte y Masullo (1999) como Gumiel (2008: 174-177) admiten que no hay ninguna restricción sobre la categoría que puede aparecer como complemento predicativo, por lo que podemos encontrar en función de complemento predicativo: a) sintagmas nominales (Isabel resultó la mejor persona), b) adjetivos (quiero las gafas obscurecidas), c) sintagmas preposicionales (compramos el pollo sin piel).

Demonte y Masullo (1999) consideran que en ejemplos como la máquina carga los paquetes en grupos de tres o encontraron a Luis de mal humor, las preposiciones que

\footnotetext{
${ }^{18}$ En su interpretación como adverbio orientado al participante.
} 
introducen los complementos predicativos convierten una expresión referencial (un nombre) en una expresión de propiedad o estado. Así pues, los sintagmas preposicionales pueden funcionar como complementos predicativos, y en la mayoría de estos casos, los sintagmas preposicionales alternan con sintagmas adjetivos.

A partir de las consideraciones anteriores, podríamos pensar que ya que no hay ninguna marca morfosintáctica, los predicativos anteriores son adjuntos generales equivalentes, por tanto, a los tradicionales complementos circunstanciales. No obstante, hay un hecho obvio, y es la relación paradigmática que existe entre encontraron a Luis de mal humor y encontraron a Luis malhumorado. La orientación hacia el controlador Luis es clara en los dos casos, y la conmutación por un adjetivo podría ser una marca formal clara para identificar el carácter predicativo descriptivo de la construcción preposicional. Es más, la imposibilidad de hacer coincidir en una misma construcción un posible predicativo preposicional y un posible predicativo adjetival sería buena prueba, también, de su identidad funcional: *encontraron a Luis despeinado de mal humor.

Por otro lado, tanto atributos como atributos no copulativos pueden ser expresados mediante sintagmas preposicionales. Ya comentamos anteriormente cómo se reconoce sin problemas para los verbos atributivos copulativos que los sintagmas preposicionales con los que se combinan funcionan como atributos, y su alternancia con adjetivos, así como la incompatibilidad de coaparición con los mismos, es buena prueba de ello:

Este vino es de La Rioja / este vino es riojano / *este vino es riojano de La Mancha ${ }^{19}$.

Parecía de cartón / parecía acartonada / *parecía acartonada de piedra.

La cama está sin hacer / la cama está deshecha / *la cama está sin hacer revuelta.

En el caso de los atributos no copulativos, es decir, los dados con verbos pseudocopulativos, que suponen una desemantización del significado y una predicación primaria (no secundaria), podríamos encontrar el mismo funcionamiento sintáctico, y dada su similitud con los verbos copulativos parece lógico pensar que también se considere indudable el carácter predicativo, y no circunstancial, del complemento preposicional orientado hacia el participante:

Pedro se hizo del Madrid / Pedro se hizo madridista / ${ }^{*}$ Pedro se hizo madridista del Barça.

Juan anda sin ganas / Juan anda desganado / Juan anda cansado sin ganas.

\footnotetext{
${ }^{19}$ La construcción este vino es riojano de La Rioja podría ser válida al entender que estamos ponderando la autenticidad de su procedencia, pero, entonces, de la Rioja no sería un SP dependiente del verbo, sino un SP dependiente de riojano, es decir, un complemento del nombre.
} 
María sigue con dolores / María sigue dolorida / ${ }^{\star}$ María sigue dolorida de mal humor.

Me encuentro con ánimos / me encuentro animado / ${ }^{\star}$ me encuentro animado con ganas de fiesta.

Tenía la camisa con manchas / tenía la camisa manchada / *tenía la camisa sucia con manchas.

El calor lo puso de mal humor / el calor lo puso malhumorado / *el calor lo puso irascible de mal humor.

Considero a Juan del Madrid / considero a Juan madridista / *considero a Juan madridista del Barça.

Imaginaba a la chica de tetas grandes / imaginaba a la chica tetona / *imaginaba a la chica inteligente de tetas grandes.

A Marta los chicos le gustan con barba / a Marta los chicos le gustan barbudos / *a Marta los chicos le gustan altos con barba.

Como hemos comprobado por el recorrido de ejemplos con atributos no copulativos y predicativos obligatorios, cuando el complemento preposicional indica una propiedad, cualidad o estado, es decir, un modo o manera, y viene referido a una determinada base atributiva, sujeto o complemento directo, funciona exactamente igual a los atributos de los verbos copulativos, y si no hay dudas acerca del estatuto atributivo de los complementos de estos, no parece que debiera haberlas en el caso de los verbos pseudoatributivos (con atributo no copulativo) y predicativos de selección obligatoria. Ahora bien, no todos los complementos preposicionales combinados con verbos copulativos son atributos.

El verbo copulativo por antonomasia, ser, se utiliza para expresar la localización (espacial o temporal) de un nombre de evento (Fernández Leborans, 1999: 2422; RAE, 2009: 2816): la conferencia es en la segunda planta. La RAE plantea la polémica de la función sintáctica del complemento con ser en estos contextos. Así, tradicionalmente se han considerado complementos circunstanciales los sintagmas preposicionales, sin embargo, otros autores sostienen que son oraciones copulativas. Es más, tal polémica afectaría también a localizaciones no ya de ubicación, sino de desplazamiento y trayectoria: el viaje será desde Lima hasta Callao, el paseo fue por la playa. En estos casos se plantea la posibilidad de entender el verbo ser como verbo soporte. También podrían entenderse construcciones con verbo soporte estructuras como el estudio era sobre el asfalto o el problema es con el director, si bien en estas últimas habría puntos de contacto con las construcciones de complemento de régimen, puesto que la preposición sobre está seleccionada por el sustantivo estudio en el primer caso, y no se descarta la posibilidad de un atributo locativo en el segundo (RAE, 2009: 2817). 
En el caso de las construcciones con estar podemos encontrar una polémica parecida: hay autores que asimilan los sintagmas preposicionales locativos a los atributos, mientras que otros encuentran más diferencias entre estos sintagmas preposicionales locativos y los adjetivos atributivos que entre los atributos y otras funciones sintácticas. Es más, si los sintagmas preposicionales locativos pueden ser predicativos (te imaginaba en el congreso, el jefe te quiere en su oficina, vi las llaves en el cenicero), en las oraciones copulativas serán atributos (el jefe está en la oficina). De igual forma, y a semejanza con ser, estar también puede tener otros usos preposicionales donde se plantee la posibilidad de atributos locativos, complementos circunstanciales, complemento de régimen o verbo de apoyo: el secretario está con el director (RAE, 2009: 2815-2818).

La conclusión que quiero extraer de este planteamiento es que, contrariamente a lo dicho en un primer momento, es posible plantear usos no atributivos con verbos copulativos. Concretamente, en el caso de las construcciones locales, sean argumentales o adjuntas ( $y$, por ello, la posibilidad de entender una construcción atributiva con circunstancial o adjunto), parece difícil admitir que constituyan el mismo tipo de función que los atributos. Otra cosa, como ya hemos comentado, es la indudable vinculación conceptual entre posesión, existencia y localización patente en todas las lenguas, y también en español (Cifuentes, 2012), con consecuencias lingüísticas, obviamente.

La necesidad de distinguir un complemento local, sea circunstancial o no, de un atributo o predicativo me parece indudable. Prueba de ello, independientemente de lo recogido al respecto por la RAE (imposibilidad de sustitución por lo: está en la oficina > *lo está, o su imposibilidad de elisión: ¿está Juan en la oficina? / ¿está Juan?, ¿está Juan enfermo? / ¿ ¿está Juan? [señalando modo o manera]), es que resultaría muy extraño pensar que dos elementos que tienen la misma función pudieran coaparecer en la misma construcción: Juan está muy contento en la oficina / estaba de pie en la oficina. Atribución local y atribución predicativa no se excluyen porque funcionan sintácticamente de forma diferente en español. Es más, el análisis planteado por la RAE acerca del carácter predicativo de sintagmas preposicionales locales me parece erróneo, pues, igual que en los ejemplos atributivos, puede coaparecer un predicativo adjetival (o preposicional) y un locativo: te imaginaba (desnuda / de pie) en el congreso, el jefe te quiere (atenta / con optimismo) en su oficina, vi las llaves (sueltas / con el llavero) en el cenicero. Si complemento local y complemento predicativo o modal no se excluyen, parece lógico concluir que sintácticamente son funciones distintas, aunque, como ya he señalado, las relaciones entre atribución y localización (y posesión) sean conceptualmente muy estrechas.

Así pues, el planteamiento señalado anteriormente en el que intentamos demostrar que son incompatibles complemento circunstancial y predicativo, no es válido, primero 
porque los complementos locales (sean circunstanciales o argumentales) son compatibles con los predicativos o atributos, y segundo, porque la prueba de conmutación del sintagma preposicional por un adjetivo no siempre se puede aplicar, e incluso aplicándose, no es concluyente.

Por ejemplo, una construcción como hablaba con la mirada perdida, podría suscitar dudas a propósito de la consideración del sintagma preposicional como predicativo, pues parece difícil encontrar un adjetivo que resuma adecuadamente la significación del sintagma preposicional: ¿hablaba ido? Por otro lado, las equivalencias semánticas son muy peligrosas. Pensemos, por ejemplo, en la indudable vinculación de predicativos con adverbios en -mente. Además, Demonte y Masullo (1999: 2490) señalan la posibilidad de entender valores adicionales de adición, compañía, instrumento y modalidad en los significados de los predicativos preposicionales.

No obstante, entendemos que hay una prueba que puede determinar el carácter funcional semejante o distinto de los predicativos o circunstanciales. Es la prueba de la coordinación (Cifuentes, 2012): si un típico atributo o predicativo adjetival puede coordinarse con un sintagma distinto (preposicional, o adverbial), consideramos que es una prueba morfosintáctica suficiente como para determinar el carácter igualitario de sus funciones (y su contrario). Dicha prueba puede venir incrementada por la consideración de pruebas adicionales, como la sustitución por un adjetivo y la coaparición, o no, de diversos sintagmas en una misma construcción.

La idea de que los elementos que se coordinan en una construcción deben realizar la misma función sintáctica cuenta con una amplia tradición gramatical, pero no recibió su formulación definitiva hasta el planteamiento de Dik (1968). Según Dik, una estructura coordinada estará caracterizada por a) poseer dos o más miembros, b) de función sintáctica idéntica, c) del mismo nivel de estructura jerárquica, d) ligados por algún tipo de nexo. Junto a la identidad funcional, Rojo (1975) ha añadido que dicha identidad funcional debe ir unida a la identidad de nivel jerárquico (lo que impediría coordinar el sujeto de una oración principal y el de una subordinada, por ejemplo), y Jiménez Juliá (1995) señala también que la condición necesaria no es tanto la homogeneidad funcional cuanto la semántica: ?Ana es espeleóloga y encantadora parece poco aceptable.

Jiménez Juliá cuestiona la equifuncionalidad con ejemplos como Juan llegó después de medianoche y borracho como una cuba (1995: 39), pues se trata de una coordinación perfectamente habitual en español y las funciones son claramente distintas (circunstancial y predicativo de sujeto, respectivamente). Este planteamiento es el que le lleva a establecer que los miembros de las estructuras coordinadas tienen como requisito básico para su coordinabilidad la alusión a nociones semánticas homogéneas, lo que tiene como consecuencia el paralelismo sintáctico de sus miembros. Tal planteamiento, sin 
embargo, es negado por Camacho (1999: 2647), al entender que ejemplos como los anteriores admiten una paráfrasis con hacerlo: Juan llegó después de medianoche y lo hizo borracho como una cuba, y entiende que sus significados son similares, lo que sugiere, por tanto, que tanto en un ejemplo como en otro se coordinan SSVV: Juan [llegó después de medianoche] y [svØ borracho como una cuba]. Así pues, al defender la coordinación de dos SSVV, es posible mantener la identidad categorial de los coordinados.

El planteamiento de Camacho parece acertado. No obstante, nos deja la duda de poder determinar cuándo estamos ante dos sintagmas funcionalmente equivalentes, $\mathrm{y}$ cuándo estamos ante dos sintagmas coordinados semánticamente, sin identidad funcional. La solución puede obtenerse a partir del análisis de Jiménez Juliá (1991: 150; 1995: 39), pues si se trata de dos sintagmas funcionalmente iguales, además de poder coordinarse (con las restricciones anteriores dadas), no podrán coaparecer en una misma construcción: Juan llegó después de medianoche borracho como una cuba. Con ello se prueba que la coordinación Juan llegó después de medianoche y borracho como una cuba no une sintagmas funcionalmente equivalentes, sino que es posible entender algún tipo de elisión en la coordinación semántica, lo que permite, en consecuencia, su coordinación sintáctica.

Otros ejemplos dados por Jiménez Juliá avalan la solución:

Compré todos los libros que quise y con muy poco dinero / compré todos los libros que quise con muy poco dinero.

Llegó muy tarde y muerto de cansancio / llegó muy tarde muerto de cansancio.

En el tiempo que estuvo de alcalde se dedicó a prohibir todo y a todos / en el tiempo que estuvo de alcalde se dedicó a prohibir todo a todos.

Bosque ha señalado la estrecha relación entre la predicación secundaria y la modificación adverbial (1996: 77), comentando que la presencia de un adverbial de manera supone la eliminación de la lectura predicativa del adjetivo: Juan compró el coche nuevo con esfuerzo, lo que legitimaría la identificación funcional entre predicativo y adverbial de manera. Sin embargo, como De Miguel y Fernández Lagunilla (2004: 35) señalan, hay ejemplos que contradicen lo anterior:

Juan se tomó el café frío con sumo placer.

Se comió la carne cruda con asco.

Comentan las autoras que no parece existir incompatibilidad entre un predicado secundario de objeto y un modificador adverbial de modo cuando este informa sobre la actitud del sujeto. Y efectivamente eso es lo que sucede, pues en el caso de se comió la carne cruda con asco, comprobamos fácilmente que cruda y con asco inciden en elementos distintos, pues no es posible la coordinación: ${ }^{\star}$ se comió la carne cruda y con asco, 
cosa que sí ocurriría en ejemplos como se comió la carne cruda y con bichitos, donde funcionarían como predicativos de CD tanto cruda como con bichitos. En el ejemplo se comió la carne cruda con asco, si aceptamos su legitimidad (cosa de la que no estoy seguro), podríamos entender los dos sintagmas como predicativos, pero uno incidiendo en el CD y el otro en el sujeto. Evidentemente, si no aparece otro predicativo y el sintagma preposicional puede coordinarse con un sintagma adjetival en función claramente predicativa, y ser sustituido, por ello, por un sintagma adjetival, su función será predicativa:

Juan se tomó el café sentado y con sumo placer.

Se comió toda la carne enfermo y con asco.

Así pues, podemos encontrar tres pruebas morfosintácticas para probar el carácter predicativo de un sintagma preposicional: a) la sustitución por un adjetivo (prueba que no es concluyente), b) la coordinación con un adjetivo, c) la no coaparición conjunta del sintagma preposicional y del sintagma adjetivo en una misma construcción. Evidentemente, las restricciones semánticas impuestas a la coordinación por Jiménez Juliá siguen siendo válidas, pues, entre otras cosas, son manifestación de la coherencia textual necesaria ${ }^{20}$.

Vamos a hacer a continuación un pequeño repaso a algunas construcciones con sintagmas preposicionales dadas como predicativos y atributos no copulativos para comprobar la aplicabilidad de las reglas anteriores y su conclusión ${ }^{21}$ :

La soprano cantó el lied con voz trémula / la soprano cantó el lied cansada / la soprano cantó el lied cansada y con voz trémula / ?la soprano cantó el lied cansada con voz trémula.

La soprano cantó el lied en zapatillas / la soprano cantó el lied descalza / la soprano cantó el lied desnuda y en zapatillas / ?la soprano cantó en lied desnuda en zapatillas.

La máquina carga los paquetes en grupos de tres / la máquina carga los paquetes atados / la máquina carga los paquetes atados y en grupos de tres / la máquina carga los paquetes atados en grupos de tres22.

\footnotetext{
${ }^{20}$ Vid. E. Ramón Trives (1982) para un interesante análisis al respecto.

${ }^{21}$ No consideramos los complementos locales por entender que ya ha quedado demostrado su carácter no predicativo: te imaginaba desnuda en el congreso / ?te imaginaba desnuda y en el congreso; el jefe te quiere atenta en su oficina / ?el jefe te quiere atenta y en su oficina; vi las llaves sueltas en el cenicero / ?vi las llaves sueltas y en el cenicero.

${ }^{22}$ La construcción es aceptable apareciendo conjuntamente tanto el sintagma adjetival (atados) como el sintagma preposicional (en grupos de tres), pero no es una excepción a la hipótesis reseñada, pues el sintagma preposicional depende del participio atados, no del verbo cargar.
} 
Encontraron a Luis de mal humor / encontraron a Luis enfadado / encontraron a Luis asustado y de mal humor / ?encontraron a Luis asustado de mal humor.

Juan come las zanahorias sin hojas / Juan come las zanahorias peladas / Juan come las zanahorias cocidas y sin hojas / Juan come las zanahorias cocidas sin hojas ${ }^{23}$.

Prefiero el té con poca azúcar / prefiero el té azucarado / prefiero el té frío y con poca azúcar / ?prefiero el té frio con poca azúcar ${ }^{24}$.

Vive con su madre / vive retirada / ?vive retirada y con su madre / vive retirada con su madre ${ }^{25}$.

Entró con sigilo / entró silencioso / entró silencioso y con sigilo / ?entró silencioso con sigilo.

Iba a la iglesia con enfado / iba a la iglesia enfadado / iba a la iglesia forzado y con enfado / ?iba a la iglesia forzado con enfado.

Iba a la iglesia con un libro en la mano / iba a la iglesia preparado / iba a la iglesia preparado y con un libro en la mano / iba a la iglesia preparado con un libro en la mano ${ }^{26}$.

Subió las escaleras de rodillas / subió las escaleras herido / subió las escaleras herido y de rodillas / subió las escaleras herido de rodillas ${ }^{27}$.

La llegada del corredor con el brazo en alto suscitó aplausos fervorosos / la llegada del corredor risueño suscitó aplausos fervorosos / la llegada del corredor risueño y con el brazo en alto suscitó aplausos fervorosos / la llegada del corredor risueño con el brazo en el alto suscitó aplausos fervorosos ${ }^{28}$.

Los secretarios se ponen de pie cada vez que entra el ministro / los secretarios se ponen furiosos cada vez que entra el ministro / los secretarios se ponen furiosos y de pie cada vez que entra el ministro / ?los secretarios se ponen furiosos de pie cada vez que entra el ministro.

\footnotetext{
${ }^{23} \mathrm{La}$ aceptabilidad de la construcción tampoco es un contraejemplo a nuestra hipótesis, pues recordando lo señalado más arriba, la aceptabilidad de la construcción solo es posible si cocidas es interpretado como modificador del nombre, es decir, no como predicativo.

${ }^{24}$ Mismo comentario que en la nota anterior.

${ }^{25} \mathrm{La}$ construcción preposicional presenta dudas acerca de su aceptabilidad como predicativo, aunque en vive retirada con su madre, el SP depende de retirada, no del verbo. En principio, a no ser que otra coordinación hiciera coherente semánticamente la construcción, debiéramos considerar a la construcción preposicional no predicativa, es decir, circunstancial.

${ }^{26} \mathrm{La}$ construcción es gramatical al depender el SP del participio, no del verbo.

${ }^{27}$ Misma explicación que en la nota anterior.

${ }^{28}$ La coaparición de SA y SP es adecuada pero siempre y cuando el adjetivo deje de funcionar como predicativo y se entienda como modificador del sustantivo.
} 
Las circunstancias se volvían en nuestra contra / la circunstancias se volvían contrarias / las circunstancias se volvían peligrosas y en nuestra contra / ?las circunstancias se volvían peligrosas en nuestra contra.

María sigue con dolor de cabeza / María sigue dolorida / María sigue enfadada y con dolor de cabeza / ?María sigue enfadada con dolor de cabeza.

Enviaron la carta sin sello / enviaron la carta abierta / enviaron la carta abierta y sin sello / ?enviaron la carta abierta sin sello ${ }^{29}$.

No se puede pisar con los pies descalzos / no se puede pisar descalzo / no se puede pisar desnudo y con los pies descalzos / ?no se puede pisar desnudo con los pies descalzos.

Viene con las manos en los bolsillos / viene sonriente / viene sonriente y con las manos en los bolsillos / ?viene sonriente con las manos en los bolsillos.

La conclusión que podemos obtener, por tanto, del análisis efectuado es que los sintagmas preposicionales pueden funcionar como predicativos y como atributos no copulativos, aunque no en todas las ocasiones que ha sido señalado, sino cuando cumplen las pruebas anteriormente señaladas ${ }^{30}$. Desde el momento en que los predicativos preposicionales pueden marcarse sintácticamente con las pruebas anteriores, entendemos que, en español, es prueba suficiente como para identificarlos (los casos que correspondan) como descriptivos, y no como adjuntos generales, desde una perspectiva tipológica de las lenguas, es decir, es una prueba de marcación sintáctica de su funcionamiento descriptivo, semejante a la concordancia de los adjetivos. Sigue vigente todo lo señalado a propósito del continuo de la expresión de manera.

\section{Conclusiones}

1. Atributo, predicativo y complemento de modo forman un continuo.

2. Distinguimos atributo de predicativo por el tipo de predicación atributiva asertada: secundaria en el caso de los predicativos y primaria en el caso de los atributos.

3. El verbo atributivo suele llevar aparejada una desemantización en su significado.

4. Predicativo y complemento de modo orientado al participante están diferenciados mediante marcación sintáctica: por concordancia entre predicativo y base de la atribución cuando se trata de un adjetivo, y mediante sustitución por un adjetivo,

\footnotetext{
${ }^{29}$ La construcción es aceptable siempre y cuando el participio no se considere predicativo, sino modificador del sustantivo.

${ }^{30}$ Somos conscientes de que en ocasiones puede ser dudosa la aceptabilidad o no de alguna de las construcciones combinadas.
} 
concordancia con un adjetivo y no coaparición conjunta con un sintagma adjetivo cuando se trata de sintagmas preposicionales.

5. Atributo, predicativo y complemento de modo distinguen distintos subtipos, lo que hace más ligera la transición entre los mismos.

6. Tanto verbos con atributo como verbos con predicativo permiten usos no atributivos bajo determinadas condiciones.

7. Predicativos y atributos están marcados en español: mediante concordancia en el caso de adjetivos, y mediante pautas sintácticas en el caso de los sintagmas preposicionales.

Recibido: 04-II-2011

Aceptado: 16-IX-2011

\section{Referencias bibliográficas}

Alarcos Llorach, E. (1990): "La noción de suplemento". En Homenaje a Francisco Marsá. Barcelona, Universidad de Barcelona, págs. 209-221.

Arrivé, M., F. Gadet, et M. Galmiche (1986): La grammaire d'aujourd'hui. París, Flammarion.

Bartsch, R. (1976): The Grammar of Adverbials. Amsterdam, North-Holland.

Benveniste, É. (1966): Problèmes de linguistique générale I. París, Gallimard.

Bonnard, H. (1971): Grand Larousse de la Langue Française, (attribut: 302-309, complement: 832-833).

Bosque, I. (ed.) (1996): El sustantivo sin determinación. Presencia y ausencia de determinante en la lengua española. Madrid, Visor.

Camacho, J. (1999): “La coordinación”. En Bosque, I. y V. Demonte (dirs.): Gramática Descriptiva de la Lengua Española. Madrid, Espasa-Calpe, págs. 2635-2694.

Campos, H. (1999): "Transitividad e intransitividad". En Bosque, I. y V. Demonte (dirs.): Gramática Descriptiva de la Lengua Española. Madrid, Espasa-Calpe, págs. 1519-1574.

Cano Aguilar, R. (1999): "Los complementos de régimen verbal". En Bosque, I. y V. Demonte (dirs.): Gramática Descriptiva de la Lengua Española. Madrid, EspasaCalpe, págs. 1807-1854.

Carrasco Gutiérrez, Á. (1999): "El tiempo verbal y la sintaxis oracional. La consecutio temporum”. En Bosque, I. y V. Demonte (dirs.): Gramática Descriptiva de la Lengua Española. Madrid, Espasa-Calpe, págs. 3061-3128.

Cifuentes Honrubia, J. L. (1994): Gramática cognitiva. Fundamentos críticos. Madrid, Eudema. 
Cifuentes Honrubia, J. L. (2011): "Predicativo y complemento de modo". En Enghels, R., M. Meulleman y C. Vanderschueren (2011) (eds.): Peregrinatio in Romania. Artículos en homenaje a Eugeen Roegiest con motivo de su 65 cumpleaños. Gante, Academia Press, págs. 51-78.

Cifuentes Honrubia, J. L. (2012): "Predicative constructions and locative alternations in Spanish and Romance languages", Linguistics Applied, 5, (en prensa).

Cifuentes Honrubia, J. L. y J. L. Tornel Sala (1996): “Iconicidad y gramática: el predicativo en español", $L E A, 18-1$, págs. 17-47.

De Groot, C. (2008): "Depictive Secondary Predication in Hungarian". En Schroeder, Chr., G. Hentschel y W. Boeder (eds.): Secondary predicates in Eastern European languages and beyond. Oldenburg, BIS-Verlag der Carl von Ossietzky-Universität, págs. 69-96.

De Groot, C. (2009): "Oriented Adjuncts and Representational Frames: Depictives and Manner in Hungarian”: http://home.medewerker.uva.nl/c.degroot/bestanden/De \%20Groot\%20 Oriented\%20Adjuncts\%20ICSH9\%202009.pdf.

De Groot, W. (1948): “Structural linguistics and word classes”, Lingua, 1, págs. 427-500.

De Miguel Aparicio, E. y M. Fernández Lagunilla, (2004): "Un enfoque subeventivo de la relación entre predicados secundarios y adverbios de manera", Revue Romane, 39-1, págs. 24-44.

Demonte, V. y P. J. Masullo (1999): "La predicación: los complementos predicativos". En Bosque, I. y V. Demonte (dirs.): Gramática Descriptiva de la Lengua Española, Madrid, Espasa-Calpe, págs. 2461-2523.

Dick, S. C. (1968): Coordination. Its Implications for the Theory of General Linguistics. Amsterdam, Holland.

Dick, S. C. et alii (1990): "The hierarchical structure of the clause and the typology of adverbial satellites". En Nuyts, J., A. Machtelt Bolkestein y C. Vet (eds.): Layers and Levels of Representation in Language Theory. Amsterdam, John Benjamins, págs. 25-70.

Dowty, D. R. (2003): “The dual analysis of adjuncts/complements in Categorial Grammar". In Lang, E., C. Maienborn y C. Fabricius-Hansen (eds.): Modifying Adjuncts. Berlín, de Gruyter, págs. 33-66.

Eckardt, R. (1998): Events, Adverbs, and Other Things. Tubinga, Niemeyer.

Ernst, T. (2000): Manners and Events, Ms., Universidad de Rutgers.

Fernández Leborans, M. (1999): "La predicación: las oraciones copulativas". En Bosque, I. y V. Demonte (dirs.): Gramática Descriptiva de la Lengua Española. Madrid, Espasa-Calpe, págs. 2357-2460.

Frey, W. y K. Pittner (1998): "Zur Positionierung von Adverbialen im deutschen Mittelfeld”, Lingusitische Berichte, 176, págs. 489-534. 
Geuder, W. (2002): Oriented Adverbs. Issues in the Lexical Semantics of Event Adverbs, $\mathrm{Ph}$. Dissertation:

http://tobias-lib.uni-tuebingen.de/volltexte/2002/546/pdf/geuder-oriadverbs.pdf

Goes, J. (2009): “Attribution et manière”, Langages, 175, págs. 85-102.

Golay, J. P. (1959): "Le complement de manière est-il un complément de circonstance?”, Le français moderne, XXVII, págs. 65-71.

Gumiel Molina, S. (2005): Los complementos predicativos. Madrid, Arco Libros.

Gumiel Molina, S. (2008): Estructura argumental y predicación secundaria. Madrid, Universidad de Alcalá de Henares.

Gutiérrez Ordóñez, S. (1987): Variaciones sobre la atribución. León, Universidad de León.

Gutiérrez Ordóñez, S. (1994): “Nuevas variaciones sobre la atribución”. En Serra, E, B. Gallardo et alii (comps.): Panorama de la investigació lingüística a l'Estat Espanyol. Valencia, Universidad de Valencia, I, págs. 31-54.

Haeseryn, W. (ed.): Algemene Nederlandse Spraakunst. Groningen, Wolters-Noordhoff.

Halliday, M. A. K. (1966): "Notes on transitivity and theme in english, Part 1", Journal of Linguistics, 3, págs. 37-81.

Hernanz, M. Ll. y A. Suñer (1999): “La predicación: la predicación no copulativa. Las construcciones absolutas". En Bosque, I. y V. Demonte (dirs.): Gramática Descriptiva de la Lengua Española. Madrid, Espasa-Calpe, págs. 2525-2560.

Higginbotham, J. (1989): "Elucidations of Meaning", Linguistics and Philosophy, 12, págs. 465-517.

Himmelmann, N. P. \& E. Schultze-Berndt (2005): "Issues in the syntax and semantics of participant-oriented adjuncts: an introduction”. En Himmelmann, N. P. y E. Schultze-Berndt (eds.): Secondary Predication and Adverbial Modification. Oxford, Oxford University Press, págs. 1-67.

Jackendoff, R. (1972): Semantic Interpretation in Generative Grammar. Cambridge, MIT Press.

Jiménez Juliá, T. (1991): “Sobre neutralización y funciones sintácticas”, Verba, 18, págs. 129-164.

Jiménez Juliá, T. (1995): La coordinación en español: aspectos teóricos y descriptivos. Santiago de Compostela, Universidad de Santiago de Compostela.

Kovacci, O. (1999): “El adverbio". En Bosque, I. y V. Demonte (dirs.): Gramática Descriptiva de la Lengua Española. Madrid, Espasa-Calpe, págs. 705-786.

Langacker, R. (2004): "Posesion, Location, and Existence". En Soares da Silva, A., A. Torres e M. Gonçalves (eds.): Linguagem, cultura e cognição. Estudos de lingüística cognitive. Coimbra, Almedina, págs. 85-120. 
López, Á. y R. Morant (2002): “L’adverbi”. En Solà, J., M. R. Lloret, J. Mascaró y M. Pérez Saldanya (dirs.): Gramàtica del català contemporani. Barcelona, Editorial Empúries, vol. 2, págs. 1797-1852.

Martínez García, H. (1986): El suplemento en español. Madrid, Gredos.

McConell-Ginet, S. (1982): "Adverbs and Logical Form: A Linguistically Realistc Theory”, Language, 58, págs. 144-184.

Moure, M. T. (1995): "Sobre el carácter no-discreto de la complementación clausal", Revista de Filología de la Universidad de La Laguna, 14, págs. 109-139.

Müller, S. (2004): "An Analysis of Depictive Secondary Predicates in German without Discontinuous Constituents". En Müller, S. (ed.): Proceedings of the HPSG-2004 Conference, Center for Computational Lingusitics, Katholieke Universiteit Leuven. Stanford, CSLI Publications, págs. 202-222.

Müller, S. (2008): "Depictive Secondary Predicates in German and English": http://hpsg.fu-berlin.de/ stefan/PS/oldenburg-depictives.pdf.

Müller-Bardey, T. (2005): “Adverbials and depictives as restrictors”. En Himmelmann, N. P. y E. Schultze-Berndt (eds.): Secondary Predication and Adverbial Modification. Oxford, Oxford University Press, págs. 107-140.

Navas Ruiz, R. (1977): 'Ser' y 'estar'. El sistema atributivo del español. Salamanca, Almar.

Navas Ruiz, R. y C. Moreno (1984): 'Ser' y 'estar'. La voz pasiva. Salamanca, Almar.

Nichols, J. (1978): “Secondary predicates”, Berkeley Linguistics Society, 4, págs. 114-127.

Nichols, J. (1981): Predicate Nominals: A Partial Surface Syntax of Russian. Berkeley, University of California Press.

Palancar, E. L. y L. L. Alarcón Neve (2007): "Predicación secundaria depictiva en español”, RSEL, 37, págs. 337-370.

Penadés Martínez, I. (1994): Esquemas sintáctico-semánticos de los verbos atributivos del español. Alcalá de Henares, Universidad de Alcalá de Henares.

Plank, F. (1985): "Prädikativ und Koprädikativ", Zeitschrift für Germanistische Linguistik, 13-2, págs. 154-185.

Platt, J. T. y H. K. Platt (1972): “Orientation of manner adverbials”, Papers in Linguistics, págs. 227-249.

Porroche Ballesteros, M. (1990): Aspectos de la atribución en español. Zaragoza, Pórtico.

Quirk, R. et alii (1985): A Comprehensive Grammar of the English Language. Londres, Longman.

R.A.E. (2009): Nueva Gramática de la Lengua Española. Madrid, Espasa-Calpe.

Ramón Trives, E. (1982): Estudios sintáctico-semánticos del español I. La dinámica interoracional. Murcia, Godoy.

Ramos, J. R. (2002): "La predicació no verbal obligatòria”. En Solà, J., M. R. Lloret, J. 
Mascaró y M. Pérez Saldanya (dirs.): Gramàtica del català contemporani. Barcelona, Editorial Empúries, vol. 2, págs. 1951-2044.

Rigau, G. (2002): "Els complements adjunts". En Solà, J., M. R. Lloret, J. Mascaró y M. Pérez Saldanya (dirs.): Gramàtica del català contemporani. Barcelona, Editorial Empúries, vol. 2, págs. 2045-2110.

Rodríguez Díez, B. (1982): “L’attribut en espagnol: essai d’une description et classification fonctionnelles", Linguistique, 18-2, págs. 33-48.

Rodríguez Ramalle, T. M. (2001): "Los adverbios de manera como predicados de los subeventos verbales", RSEL, 31-1, págs. 107-143.

Rojo, G. (1975): "Sobre la coordinación de adjetivos en la frase nominal y cuestiones conexas", Verba, 2, págs. 193-224.

Schäfer, M. (2008): "Resolving scope in manner modification". En Bonami, O. y P. Cabredo Hofherr (eds.): Empirical Issues in Syntax and Semantics, 7, págs. 351-372.

Schultze-Berndt, E. y N. P. Himmelmann (2004): "Depictive secondary predicates in crosslinguistic perspective”, Linguistic Typology, 8, págs. 59-131.

Simpson, J. (2005): "Depictives in English and Warlpiri". En Himmelmann, N. P. y E. Schultze-Berndt (eds.): Secondary Predication and Adverbial Modification. Oxford, Oxford University Press, págs. 69-106.

Taverniers, M. y G. Rawoens (2010): “Three Types of Oriented Adjuncts in English and Swedish”, Moderna språk, 1, págs. 1-14.

Van der Auwera, J. \& A. Malchukov (2005): "A semantic map for depictive adjectivals". En Himmelmann, N. P. y E. Schultze-Berndt (eds.): Secondary Predication and Adverbial Modification. Oxford, Oxford University Press, págs. 393-421.

Wagner, R. y J. Pinchon (1962): Grammaire du français classique et modern. París, Hachette.

Wyner, A. (1998): "Subject-oriented adverbs are thematically dependent". En Rothstein, S. (ed.): Events and Grammar. Dordrecht, Kluwer, págs. 333-348. 